Sérgio Mendes

\title{
Captação pelo carcinoma de mama e pelo linfonodo axilar de uma nanoemulsão lipídica administrada por injeção no tecido mamário locorregional
}

Tese apresentada à Faculdade de Medicina da Universidade de São Paulo para obtenção do título de Doutor em Ciências

Área de concentração:

Distúrbios Genéticos de Desenvolvimento e Metabolismo

Orientador:

Prof. Dr. Raul Cavalcante Maranhão 
Aos meus pais, Licurgo e Maria Mendes, sem cuja guarda, proteção, amor e estima tão difícil seria caminhar nos atalhos da vida. 
Deixo aqui consignada especial e profunda gratidão

Ao Professor Doutor Raul Cavalcante Maranhão modelo impar de dignida de e profissiona lismo. Foi enome honra poder ter sido acolhido pelo Senhor.

A Professora Angela Maggio da Fonseca portoda a sua ajuda nestes anos de convivência, sua proteção nas horas tão difíc eis e principa Imente, me ensina ndo que a simplicidade e a honestidade vencem sempre. 


\section{AGRADEC IMENTOS}

A Dra. Silvia Graziane, pela inestimável colaboração na idealização e no desenvolvimento deste estudo.

Ao Professor Doutor Edmund Cha da Baracat, professor titular de Ginecologia do Departamento de Obstetrícia e Ginecologia da Faculdade de Medicina da Universidade de São Paulo pela confiança em mim depositada, pelo seu estímulo e orientação.

Ao Professor Doutor Roberto Hegg, pela colaboração na viabilidade desta tese.

A pós graduanda Tatiane Solano e a Doutora Amanda Padoveze a Débora Deus pela inestimável colaboração na realização deste projeto.

A Doutora Carmem Guilherme Vinagre pela sua atenção por mim dedicado.

Ao Doutor Luiz Ignácio Pettoruti, sem seu estímulo e colaboração valiosa, jama is seria possível a rea liza ção deste projeto.

Ao DoutorJ osé Roberto Piato, pela saudável companhia, orientação e presença nas horas mais críticas desta minha importante jornada.

A Doutora Marianne Pinotti pela sua importante ajuda e grande interesse para que este projeto fosse concluído 
A Claudia Aparecida Vieira, pela sua delic adeza cotidiana, sua sempre disponibilidade e incentivo para finalização desta tese. Você é para mim uma verdadeira amiga, por tudo que você testemunhou nestes anos.

Ao Professor Doutor Nilson Roberto de Melo, pelo seu estímulo, presença e orientação quando não havia ma is direção a seguir.

Ao Professor Doutor J osé Aristodemo Pinotti, primeiro por ter me feito compreender a importância da carreira acadêmica; segundo, por ter me convencido a ingressar no curso de pós-graduação e lá, ter me acolhido com grande respeito.

Aos Professores Doutores Vic ente Renato Bagnoli, Henri Friedhofer e Luiz J orge Fagundes que, com estímulos constantes e presença sempre continente, colocam verdadeiramente em prática todos os conceitos embutidos no termo "amizade".

Ao Doutor J oão Carlos Salvestrin, pessoa a quem devoto grande admiração.

Ao Doutor Jair de Oliveira, pela saudável e hamoniosa companhia e pelo verdadeiro companheinsmo e imandade nestes anos todos de nossasca reirase "correrias".

A Angélica Belém de Souza, Rose Cler Ferreira, e Sheila Vasconcelos Va lentin Loyolla pela sua grande disponibilidade e atenção a mim dedicada.

Ao meu imão Silvio Mendes, minha cunhada Maria de Lourdes, 
e minhas sobrinhaslalê, Inara, lone pela importância e influência em minha vida profissional e pessoal.

Ao Serviço de Pós-Graduação, em especial a Sra.Yara Carradini pelo apoio, orientação e atenção a mim dedicado.

A CAPPesq em especial a Sra. Márcia Aparecida Teixeira de Carvalho, sua enome presteza foi fundamental na elaboração e realização deste projeto.

Aos imãos de alma e coração Petrônio Pinheiro Machado e Valdir Geraldo, porque sempre há de ter alguém que nos estende uma mão, mas sem empurrar com a outra. 


\title{
Lista de abreviaturas
}

\author{
HDL High density lipoprotein (Lipopreoteína de alta densidade) \\ LDE Emulsão lípidica de baixa densidade \\ LDL Low density lipoprotein (Lipopreoteína de baixa densidade) \\ LMA Leucemia mielocítica aguda \\ LS Linfonodo sentinela \\ LTI Linfonodos da torácica interna \\ r-LDL Receptor de LDL \\ VLDL Very low density lipopreotein (Lipopreoteína de muito baixa densi- \\ dade) \\ ApoB Apoliproteína B-100 \\ HMGCoA 3-hidroxil-3-metilglutaril-Co-A-redutase \\ redutase \\ PCR Reação em cadeia da polimerase \\ RNA Ácido ribonucléico
}




\section{Lista de tabelas}

Tabela 1 Idade das pacientes e tipo de cirurgia realizadas no estudo

Tabela 2 Dados do diagnóstico anatomopatológico, estadiamentos cirúrgico e clínico da doença e resultados da análise imuno-histoquímica nas 14 pacientes incluídas no estudo

Tabela 3 Concentrações (em $\mathrm{mg} / \mathrm{dl}$ ) de triglicérides, colesterol total e frações em sangue coletado 12 horas antes da cirurgia nas 14 pacientes no estudo

Tabela 4 Captação de LDE em cpm/g de tecido normal de mama, tecido tumoral, e lifonodo axilar nas 14 pacientes divididas em grupos, de acordo com o local da injeção

Tabela 5 Captação de LDE em cpm/g pelos linfonodos comprometidos e não comprometidos nas 14 pacientes incluídas no estudo divididas em grupos, de acordo com o local da injeção de LDE

Tabela 6 Correlação do peso da mama, peso do tumor e porcentagem do tumor em relação à mama com a de captação da LDE em tecido normal, tecido tumoral e linfonodos. 


\section{Lista de figuras}

Figura 1 Curvas relativas à radioatividade $(\mathrm{cpm} / \mathrm{ml})$ encontrada no plasma coletado até 24 horas após a injeção de LDE nos três grupos de estudo 


\section{Resumo}

Mendes, S. Captação pelo carcinoma de mama e pelo linfonodo axilar de uma nanoemulsão lipídica administrada por injeção no tecido mamário locorregional [tese]. São Paulo: Faculdade de Medicina, Universidade de São Paulo, 2008. 77p.

Em trabalhos anteriores, mostrou-se que uma nanoemulsão lipídica denominada LDE após injeção endovenosa, em pacientes com carcinoma mamário e outros tumores sólidos concentra-se nos tecidos neoplásicos e pode direcionar especificamente agentes quimioterápicos ao tumor. Estudos clínicos mostraram que a LDE diminui acentuadamente os efeitos tóxicos desses agentes e em estudos com animais de experimentação não reduz seus efeitos antitumorais. No presente estudo, testamos a hipótese de a LDE injetada por via locorregional poderia concentrar-se no tumor de mama e nos linfonodos axilares da mama comprometida, visando futuras aplicações do sistema na quimioterapia neoadjuvante desse tumor. Três técnicas de injeção da LDE foram testadas em pacientes com carcinoma de mama avançado com tratamento cirúrgico pré-programado. A LDE marcada com colesterol radioativo foi injetada 12 horas antes da cirurgia, nas pacientes divididas em três grupos: Grupo $1(\mathrm{G} 1, \mathrm{n}=4)$ : $L D E$ injetada no parênquima mamário, a $5 \mathrm{~cm}$ da lesão ; Grupo 2 (G2, n=4): LDE injetada na região peritumoral; e Grupo 3 (G3 n=6): LDE injetada em região intratumoral. Este grupo foi subdividido em 2: em 2 pacientes realizaram cirurgia 2 hs após a injeção da LDE e nas outras $4,12 \mathrm{hs}$ após a injeção da LDE. Quantificou-se a captação da LDE nos fragmentos de tecido tumoral e mamário normal e do linfonodo axilar retirados durante a cirurgia por contagem de radioatividade após extração lipídica dos tecidos. Os resultados evidenciaram que, em $\mathrm{G} 1$, houve maior captação da LDE em tecido normal, sugerindo se tratar de metodologia inadequada. Em G2, a captação da LDE foi quatro vezes maior no tecido tumoral do que no tecido normal, próximo, portanto, dos valores encontrados em estudos anteriores que utilizaram a injeção da LDE por via hematológica. Em G3, o valor médio de captação da LDE foi 53 vezes maior no tecido tumoral $(>75 \%)$, com mínima captação pelo tecido mamário normal $(<8 \%)$. A injeção intratumoral da LDE mostrou-se, portanto, metodologia ainda superior à injeção da LDE por via endovenosa para a utilização efetiva dessa nanoemulsão como terapia-alvo em tumores primários de mama.

Descritores: Neoplasia mamária; quimioterapia; nanoparticulas lipídicas; Lipoproteínas LDL. 


\section{Abstract}

Mendes, S. Capture by breast carcinoma and the axillary lymph node of a lipidic nanoemulsion injected into the locoregional breast tissue. [thesis]. São Paulo: Faculdade de Medicina, Universidade de São Paulo, 2008. 77p.

In previous work had showed that a lipidic nanoemulsion called LDE after intravenous injection in patients with breast carcinoma and others solid tumors focuses in the neoplasic tissue and can target especially chemotherapist agents to the tumors. Clinical studies showed that LDE decreases the toxic effects of those agents and in studies with experimental animals don't reduce yours antitumoral effects. In the present study, we had test the hypothesis of the LDE injected by locoregional could focuses in the breast tumor and in the axillary lymph node of the compromised breast, targeting future applications of the system in the neoadjuvant chemotherapy of this tumor. Three techniques of injection of the LDE had test in patients with advanced breast carcinoma with sirurgic treatment pre-programmed. The LDE marked with radioactive cholesterol was injected 12 hours before the surgery, in patients divided in three groups: Group $1(\mathrm{G} 1, \mathrm{n}=4)$ : LDE injected in the breast parenchyma, about $5 \mathrm{~cm}$ of the lesion; Group 2 (G2, $n=4)$ : LDE injected in the peritumoral region; and Group 3 (G3, n=6): LDE injected in the intratumoral region. This group was subdivided in 2: in 2 patients had realized surgery $2 \mathrm{hs}$ after the injection of LDE and in the others 4 patients $12 \mathrm{hs}$ after the injection of LDE. It had quantified the capture of LDE in the fragments of the tumoral and breast tissue and of the axillary lymph node withdrawn during the surgery by counting of radioactive after lipidic extraction of this tissue. The results showed that, in $\mathrm{G} 1$, there was greater capture of LDE in normal tissue, suggesting it is an inappropriate methodology. In G2, the capture of LDE was four times higher in the tumoral tissue than in the normal tissue, closer, therefore, of the values found in previous studies that used the injection of LDE by hematology. In G3, the medium value of capture of LDE was 53 times higher in the tumoral tissue (> $75 \%)$, with minimum capture by the normal breast tissue $(<8 \%)$. The intratumoral injection of LDE showed, therefore, methodology still higher than the intravenous injection of LDE by intravenous for the effective use of this nanoemulsion as therapy target in primary tumors of breast.

Descriptors: Breast cancer; chemotherapy; Lipidic nanoemulsion; LDL lipoprotein. 


\section{Sumário}

Lista de abreviaturas

Lista de tabelas

Lista de figuras

Resumo

Abstract

1. INTRODUÇÃO ................................................................................ 1

1.1 Lipoproteínas de baixa densidade (LDL) e câncer ............................. 1

1.2 LDL como agente direcionador de fármacos .................................... 4

1.3 LDE: Nanoemulção rica em colesterol ............................................. 7

1.4 Linfonodo sentinela e câncer de mama.......................................... 12

1.5 Justificativa.................................................................................... 17

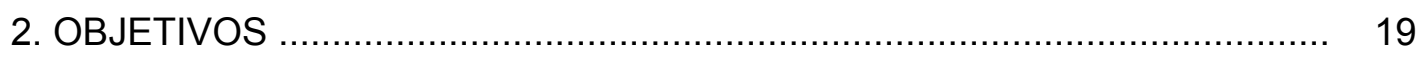

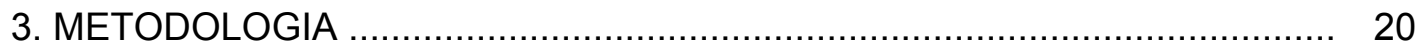

3.1 Casuística …................................................................... 20

3.1.1 Critérios de inclusão ........................................................ 21

3.1.2 Critérios de exclusão ............................................................ 21

3.1.3 Caractrerização do grupo de estudo ..................................... 21

3.2 Protocolo experimental ................................................................ 23

3.2.1 Determinações plasmáticas do perfil lipídico ........................... 25

3.2.2 Preparo da LDE .............................................................. 27

3.2.3 Determinação da cinética plasmática da LDE ....................... 29

3.2.4 Coleta do material ............................................................ 29

3.2.5 Contagem da radioatividade nas peças cirúrgicas .................. 30

3.3 Análise estatística ...................................................................... 31

4. RESULTADOS …........................................................................ 32

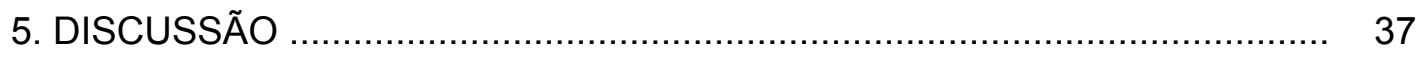

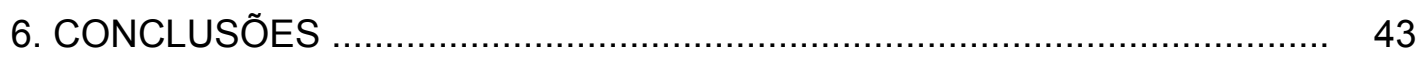

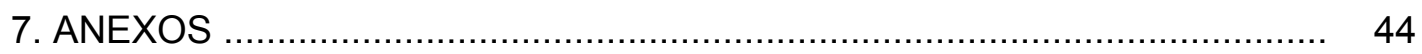

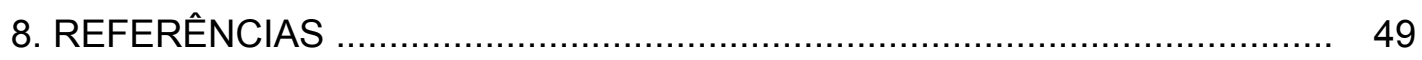




\section{INTRO DUÇÃO}

\subsection{Lipoproteínas de baixa densidade (LDL) e câncer}

As lipoproteínas de baixa densidade (LDL) desempenham papel importante no transporte de colesterol no plasma humano. Vários autores têm descrito a associação de baixos níveis plasmáticos de colesterol de LDL com doenças neoplásicas (Knapp, 1991; Mahley et al., 1984). Esta associação sugeria que os baixos níveis de colesterol seriam fator predisponente ao desenvolvimento de neoplasias malignas. No entanto, mostrou-se posteriormente que é resultado da maior captação da LDL pelas células neoplásicas, determinada pela necessidade de lípides para a síntese de novas membranas celulares. Isto permite o aumento descontrolado na freqüência de mitose celular característico do câncer (Ho et al, 1978). Como veremos, este fenômeno também é a base para uma nova estratégia de tratamento da doença.

A LDL é uma partícula esférica composta por um núcleo de éster de colesterol e triglicérides, circundada por uma monocamada de fosfolipídios e colesterol livre. Liga-se aos receptores de LDL (rLDL) por meio de domínios presentes na apoliproteína B-100 (apoB-100), que se encontra ancorada na monocamada de fosfolipídios e que representa $20 \%$ do peso da partícula (Eisenberg, 1980).

A meia-vida plasmática da LDL é de dois a três dias. O fígado é o prin- 
cipal órgão de remoção plasmática da LDL, e é responsável por $70 \%$ de sua degradação. Entretanto, quase todos os tecidos do organismo expressam rLDL. Esses receptores se encontram em regiões específicas nas depressões da membrana celular que são revestidas por proteínas denominadas clatinas. Após a interação das lipoproteínas com os receptores, essa região sofre invaginação, formando vesículas endocíticas compostas de clatrina, a proteína de sustentação da célula. O envoltório de clatrina, então, funde-se com lisosomas, formando endossomas. A diminuição do pH no interior dos endossomas desidrata a parede das vesículas, que se rompem e liberam no citosol os componentes lipídicos e os produtos de lise protéica da LDL. O receptor é reciclado, retornando para a superfície celular (Goldstein et al., 1979).

O rLDL tem estrutura protéica composta por uma única cadeia com 839 resíduos de aminoácidos, está presente em grande variedade de tecidos e apresenta maior atividade justamente nos tecidos em que o colesterol é mais requisitado. O número de rLDL na superfície das células é regulado pela necessidade de colesterol para a síntese de membranas, hormônios esteróides e ácidos biliares (Knapp, 1991).

Além da captação celular mediada por receptor, a demanda de colesterol pode ainda ser suprida por síntese endógena e monitorada pelo aumento da atividade da enzima 3-hidroxi-3-metilglutaril-Co-A-redutase (HMG CoA redutase), que é a enzima-chave da biossíntese de colesterol. O excesso de colesterol intracelular ativa a ação da enzima acil-Co-A-colesterolaciltransferase (ACAT) que esterifica o colesterol que é estocado na forma 
de gotículas (Erickson \& Cooper, 1980).

Quando as células estão desprovidas de colesterol, ocorre aumento de expressão do rLDL e da atividade da HMG CoA redutase. A síntese intracelular de colesterol e dos receptores B/E varia na razão inversa da captação do colesterol plasmático. O rLDL está sujeito à regulação retroativa, que é o principal fator para o controle da concentração plasmática de LDL (Brown et al., 1981).

Em estudo pioneiro realizado em 1978, Ho et al. observaram aumento na atividade do rLDL nas células leucêmicas do sangue periférico de pacientes com leucemia mielóide aguda, em relação às células mononucleares de indivíduos sadios. Nesse estudo ficou demonstrado que o aumento de receptores nas células neoplásicas é um fenômeno muito intenso, podendo ser de três a 100 vezes maior do que o número de receptores presentes em células normais. O aumento da atividade dos rLDL leva ao aumento de captação da lipoproteína pela célula neoplásica. Com isto, é criada uma via extra de saída de colesterol do compartimento plasmático e, em conseqüência, diminuem os níveis de colesterol de LDL no plasma.

O fenômeno de superexpressão dos rLDL, no entanto, não é restrito às neoplasias hematológicas, ocorrendo também em tumores sólidos. Em 1981, Gal et al. mostraram que células de linhagem neoplásica , como o carcinoma epidermoidal vaginal, carcinoma epidermóide cervical e adenocarcinoma endometrial) expressavam cerca de 15 a 30 vezes mais rLDL do que células de linhagem normal (células fibroblásticas cervicais e células epiteliais de glândula endometrial).

Posteriormente, vários estudos confirmaram o aumento de expressão de 
rLDL em melanoma (Villman et al, 2007), câncer de mama (Rudling et al., 1986), câncer de bexiga (Ueyama et al., 1990), glioma (Rudling et al., 1983), e em linhagens celulares de glioblastomas (Bellott et al., 2001; Maletinska et al., 2000) e de câncer gástrico (Tokui et al., 1995). Portanto, a superexpressão dos rLDL é um fenômeno de ampla ocorrência nas neoplasias (Budd \& Ginsberg, 1986; Henriksson et al., 1989).

Vários estudos têm matizado as alterações no metabolismo lipídico de pacientes com câncer. Já foi relatada a relação entre diminuição nos níveis de colesterol plasmático com a progressão da doença neoplásica (Iribarren et al., 1995; Pekkanen et al., 1999), assim como já foi comparada a colesterolemia encontrada em pacientes com câncer com a de indivíduos normais (Barclay et al., 1955; Bases \& Krakoff, 1965; Nydegger, 1972). Outros estudos demonstraram que os níveis plasmáticos de colesterol em pacientes com câncer se normalizam após tratamento e remissão da doença (Hungria et al., 1995; Niendorf et al., 1995).

\subsection{LDL como agente direcionador de fármacos}

O uso de LDL como agente direcionador de fármacos para as células neoplásicas tem sido explorado desde meados dos anos 1980 por diversos grupos (Rudling et al., 1983; Tokui et al., 1995; De Smidt \& Van Berkel, 1990; Lundberg, 1987; Samadi-Baboli et al., 1993; Xiao et al., 1999), e está baseado em três hipóteses que envolvem propriedades inerentes da partícula de LDL e do seu receptor (Samadi-Baboli et al., 1993): 
1) A LDL pode transportar grandes quantidades de fármacos lipofílicos que poderiam ter efeitos citotóxicos.

2) A internalização do fármaco na LDL o protegeria contra o ataque de biomoléculas plasmáticas e água.

3) O fármaco incorporado na LDL teria maior concentração nas células neoplásicas que apresentam aumento de expressão de rLDL em relação às células normais.

O primeiro relato de incorporação bem-sucedida de um agente antineoplásico à LDL data de 1984, quando Iwanick et al. prepararam um complexo de LDL com o antibiótico daunomicina, contendo, em média, 8nmol de daunomicina/mg de apolipoproteína. Nesse estudo ficou comprovado que a associação do fármaco à LDL não o modificava estruturalmente, e que as propriedades inerentes à partícula eram mantidas. Posteriormente, Masquelier et al., 1986; 2000 mostraram que agente derivado da doxorrubicina associado com LDL era captado para as células neoplásicas pelos rLDLs.

Em 1990, Vitols et al. associaram derivado insolúvel da mitoclomina à LDL e observaram que a entrada do complexo LDL-fármaco em células de ovário de Hamster normais e mutantes para rLDL foi mediada pelos rLDL. O complexo teve o mesmo comportamento plasmático que a LDL humana também em camundongos. Ainda em 1990, derivados oléicos do metrotexato e da fluoridina foram associados à LDL, resultando em aumento da meia vida plasmática do fármaco (De Smidt \& Van Berkel, 1990).

Em 1993, derivado lipofílico do eliptinium (oleato de eliptinium) foi associado à LDL numa proporção de 400 moléculas por partícula. O complexo 
formado foi metabolizado preferencialmente pelos rLDL in vitro, com aumento da atividade antitumoral demonstrado em modelo animal (Samadi-Baboli et al., 1993).

Atualmente existem vários estudos sobre a associação bem sucedida de antineoplásicos à LDL, dentre os quais se destacam a doxorrubicina (Chu et al., 2001; Kader et al., 1998), os derivados lipofílicos da daunorrubicina (Verluis et al., 1996) e os derivados lipofilícos da adriamicina (Masquelier et al., 2000). Também já foi demonstrada a incorporação de radiofármaco hidrofóbico marcado com I 125 captado pelos rLDL em três linhagens de tumores cervicais humanos (Xiao et al., 1999).

Apesar de todas as vantagens que a LDL possa oferecer como agente direcionador de fármacos, sua utilização na clínica ainda continua bastante limitada. O maior obstáculo para sua aplicação é a necessidade de isolamento do soro humano. A obtenção de LDL humana em quantidade é procedimento de alta complexidade, envolvendo plasmaferese, e com custo muito alto. A incorporação de fármacos ao produto natural é também complexa, pois pode resultar na degradação da parte protéica da lipoproteína. A perda da apoB-100 que liga a LDL aos rLDL resultaria na perda das propriedades de direcionamento de fármaco (Rensen et al., 1997). Um outro fator de aumento de custos seria a necessidade de triar os doadores para descartar doenças infecciosas, como hepatite e síndrome da imunodeficiência adquirida. Além disso, o uso de um produto sanguíneo heterológo pode produzir reações imunológicas. Todos esses inúmeros obstáculos inviabilizam na prática o uso da lipoproteína natural no tratamento do câncer. 
Mais recentemente foram relatados excelentes resultados in vitro em estudo com microemulsão lipídica com peptídeos anfifílicos, os quais se ligaram aos mesmos domínios da apoB do receptor de LDL (Baillie et al., 2002).

\subsection{LDE: Nanoemulsão rica em colesterol}

Com o intuito de desenvolver uma ferramenta para a investigação da hipercolesterolemia relacionada à arteriosclerose, Maranhão et al., 1986 estudaram o metabolismo da LDL utilizando uma nanoemulsão com composição semelhante à fase lipídica da LDL. Essa nanoemulsão denominada LDE é composta de fosfolipídios (66\%), éster de colesterol (33\%) e triglicérides (1\%), mas não contém a parte protéica da LDL humana.

Em 1993, Maranhão et al. demonstraram que a LDE aplicada a ratos se ligou aos rLDL e foi captada pelas células. Os resultados obtidos nesse estudo experimental mostraram que a LDE apresentava resposta metabólica semelhante à da LDL natural, com fortes evidências de estar sendo captada pelos mesmos receptores que retiram a LDL da circulação.

Mesmo sem conter a proteína da LDL, a LDE entra em contato com as lipoproteínas naturais ao ser injetada na circulação plasmática e adquire a apoE, que pode ser reconhecida pelo rLDL. A apoE serve, então, de ponte para a LDE ligar-se ao receptor e, assim, ser captada pela célula (Maranhão et al., 1993).

A teoria de que o meio ligante ao receptor utilizado pela LDE é a apoE, que tem mais afinidade com esse receptor do que a apoB-100 presente na 
lipoproteína natural, foi fortalecida por evidências de que a taxa de remoção plasmática de LDE se mostrou superior à da LDL em ratos, indicando que a LDE tem mais afinidade com rLDL do que a própria LDL natural (Hirata et al., 1999).

Ao se comparar o comportamento da LDE injetada em indivíduos normolipidêmicos e em portadores de hipercolesterolemia, também foi demonstrado que a LDL natural compete com a LDE pela captação celular, o que significa que ambas são removidas pelo mesmo receptor específico. Na hipercolesterolemia o defeito básico consiste em receptores $B / E$ defeituosos, o que resulta em captação deficiente da LDL e seu acúmulo no plasma. Nesses pacientes, a LDE foi removida muito lentamente da circulação, confirmando o comportamento esperado e mostrando o potencial da nanoemulsão como instrumento para investigação das dislipidemias (Maranhão et al., 1997).

Além disso, em linhagem de células de câncer de pulmão mucoepidermoidal, quantidades crescentes de LDL natural adicionadas ao meio diminuíram a captação celular da LDE, enquanto a substituição de soro fetal bovino por soro fetal deficiente em lipoproteínas fez com que as mesmas células aumentassem a expressão de rLDL e captassem mais LDE, ratificando que a LDE é de fato captada pelos rLDL (Maranhão et al., 2002).

A hipótese de que a LDE poderia substituir a LDL natural como veículo para direcionar fármacos antineoplásicos para os tecidos malignos, evitando que esses fármacos atingissem órgãos e tecidos normais, foi levantada por Maranhão et al., 1992; 1994, com base tanto nas observações então disponíveis sobre o comportamento da LDE. A nanoemulsão não apresenta riscos 
relacionados com o uso de hemoderivados, como a LDL natural, uma vez que é fabricada em laboratório a partir de materiais da indústria química.

Segundo essa hipótese, os agentes antineoplásicos seriam incorporados à LDE, e a nanoemulsão seria injetada na circulação, onde adquiriria a apoE que se ligaria preferencialmente aos rLDL das células neoplásicas, nas quais o seu número é muito maior do que nas células normais. Dessa forma, a LDE conduziria o fármaco para a célula neoplásica, aumentando a eficiência do tratamento quimioterapêutico e, ao mesmo tempo, reduzindo efeitos colaterais.

A primeira investigação a endossar essa hipótese foi realizada em pacientes com leucemia mielocítica aguda (LMA). A LDE foi removida muito mais rapidamente nos pacientes com LMA do que nos controles. Por outro lado, a remoção plasmática da LDE tornava-se mais lenta, normalizando-se aos poucos, depois de os pacientes terem sido tratados com esquemas quimioterapêuticos convencionais e de a doença ter atingido completa remissão. Isso mostrou que as células de LMA, contendo quantidades muito maiores de receptores, provocaram remoção acelerada da nanoemulsão. Quando essas células foram destruídas pela quimioterapia, a remoção normalizouse. Ressalte-se que as células leucêmicas captaram $70 \%$ da LDE injetada, o que foi observado em imagens de medicina nuclear obtidas com LDE marcada com tecnécio ${ }^{99 m}$ indicativas da captação direta da nanoemulsão pela medula óssea infiltrada de células de LMA (Maranhão et al., 1994).

Posteriormente, a captação e a concentração da LDE também foram evidenciadas em tumores sólidos. Estudos realizados em pacientes com 
câncer de ovário e mama mostraram que a LDE se concentra preferencialmente nos tecidos neoplásicos (Graziani et al., 2002; Genta, 2006).

Em pacientes com câncer de ovário, a captação da LDE injetada E.V. foi, em média, dez vezes maior no tecido neoplásico do que no tecido normal (Ades et al., 2001) e 4,5 vezes maior em pacientes com carcinoma de mama (Graziani et al., 2002; Igreja, 2000).

Esses experimentos vieram a sugerir a possibilidade de direcionamento, por via hematológica, de veículo lipídico fabricado artificialmente para o tecido neoplásico, confirmando que a LDE pode ser preferencialmente captada pelas células neoplásicas. Com isso deu-se início a uma nova etapa de investigações conduzidas pelo mesmo grupo de pesquisadores, ou seja, a incorporação de agentes quimioterápicos à LDE.

Inicialmente, o fármaco de escolha foi a carmustina devido ao seu alto grau de lipofilicidade e à facilidade de obtenção no mercado farmacêutico, sem necessidade de modificação química. Demonstrou-se, primeiro, a estabilidade da associação de carmustina à LDE por meio de ensaios realizados em cultura de células, nos quais ficou evidenciado que a atividade citostática do fármaco era preservada e que a associação LDE-carmustina era captada pelas células por meio dos rLDL. Em seguida, verificou-se que a biodistribuição de LDE-carmustina em ratos e a sua cinética plasmática em pacientes não foram alteradas pelo procedimento de associação. A captação tecidual do complexo em tumores de ovário e mama foi maior do que no tecido normal. Finalmente, em estudo clínico-piloto ficou comprovado que altas doses do complexo não provocavam efeitos adversos significativos e que, pelo 
contrário, os efeitos tóxicos da carmustina foram reduzidos pela associação com a LDE (Maranhão et al., 2002).

Outros fármacos foram depois modificados quimicamente para atingir grau de lipofilicidade adequado para a melhor incorporação com a LDE. O primeiro estudo com o complexo LDE-paclitaxel demonstrou a estabilidade da associação bem como a preservação da atividade citotóxica e a redução da toxicidade do fármaco (Rodrigues et al., 2002). Posteriormente, a transformação de paclitaxel em derivado oleato permitiu que a associação LDE-oleato de paclitaxel aplicada em modelo animal de melanoma murino mostrasse estabilidade ainda maior, sem qualquer redução da ação citotóxica do fármaco. A toxicidade do fármaco modificado foi 12 vezes inferior à do fármaco comercialmente disponível que, por sua vez, mostrou resultados inferiores aos da preparação em ensaios de regressão tumoral (Rodrigues et al., 2005).

A aplicação experimental da combinação LDE-oleato de etoposídeo a camundongos também resultou em redução dos efeitos tóxicos e melhora dos efeitos antitumorais em relação à formulação comercial (Lo Prete, 2005). A captação do fármaco em pacientes com câncer de ovário que receberam essa preparação foi quatro vezes maior no tecido tumoral do que no tecido normal do ovário contralateral (Azevedo et al., 2005). Por fim, não foi observada toxicidade importante em pacientes que receberam LDE-oleato de etoposídeo para tratamento de linfoma que, inclusive, permaneceu estável durante a o período terapêutico.

Recentemente, a combinação das preparações LDE-oleato de paclitaxel e LDE-oleato de etoposídeo foi observada como o melhor regime tera- 
pêutico em modelos experimentais de melanoma murino, com redução de efeitos tóxicos (Kretzer, 2007).

\subsection{Linfonodo sentinela e câncer de mama}

A primeira metodologia utilizada na avaliação da drenagem linfática da mama foi a linfografia com utilização do etiodol (Kinmonth \& Taylor, 1952), seguida pelo corante azul vital, proposta no final da década de 1950, quando, pela primeira vez, ficou demonstrado que a drenagem linfática ocorre da mama para a axila (Turner-Warnick, 1959). Posteriormente, foi reportada a descoberta do primeiro colóide ligado ao nucleotídeo Tc-99m, iniciando-se a era da linfocintilografia (Keshtgar et al., 2000).

A expressão "linfonodo sentinela" (LS) define o principal linfonodo a receber a drenagem de um carcinoma. Foi utilizada pela primeira vez em 1960, quando Gould et al. estudaram o câncer de parótida. Em 1977, Cabanãs descreveu o conceito fisiológico do LS após estudo de 80 casos de câncer de pênis, no qual concluiu que, quando a biópsia do LS era negativa para metástase, não havia necessidade de nenhuma complementação cirúrgica para retirada dos outros linfonodos.

No que concerne ao câncer de mama, os critérios de seleção de pacientes e as técnicas de identificação do LS variaram amplamente em diferentes estudos. Por exemplo, para alguns estudos, foram selecionadas apenas pacientes com tumores primários intactos (Albertini et al., 1996; Veronesi et al., 1997). Na maioria dos relatos, o colóide marcado radioativamente foi in- 
jetado nas proximidades do tumor (Albertini et al., 1996; Alex \& Krag, 1993; Krag et al., 1993), enquanto outros autores o aplicaram por injeção subdérmica (Veronesi et al., 1997). A dose de radioatividade, o intervalo entre a injeção e a operação, e o uso de linfocintilografia também variam entre os relatos. Mas, apesar dessas variações na seleção de pacientes e técnicas de mapeamento, a experiência permite a identificação de LS em mais de $90 \%$ dos casos e o estado dos linfonodos axilares restantes podem ser prognosticados com 95\% de acurácia (Klimberg et al., 2002).

O conceito de LS implica na compreensão do processo de propagação das células tumorais, reforçando a noção de que o fluxo ocorre em padrão ordenado, disseminando as células metastáticas de modo seqüencial em cascata. O LS pode predizer o estado histológico dos linfonodos regionais que o acompanham, orientando a conduta cirúrgica (Mariani et al., 2001). Entretanto, é possível que o LS esteja livre de comprometimento metastático, enquanto os linfonodos seguintes sejam sede de metástases (metástases saltatórias), mas se trata de ocorrência rara, especialmente quando o tumor primário está em estádio inicial de crescimento (Mariani et al., 2001).

Em 1999, foi implementado nos Estados Unidos o "National Surgical Adjuvant Breast and Bowel Project (NSABP)", ensaio clínico randomizado envolvendo 59 centros e 149 cirurgiões, cujo objetivo foi a comparação do LS biopsiado com os linfonodos axilares extirpados em mulheres com câncer de mama elegíveis para o procedimento (Harlow \& Krag, 2001). Os resultados desse estudo multicêntrico demonstraram o real significado das variáveis envolvidas com a preservação dos linfonodos axilares e foram assim 
estabelecidas diretrizes para essa nova tecnologia.

A biópsia de LS permite ao patologista a oportunidade de executar estudo muito mais detalhado do linfonodo mais provável de conter metástase do que é possível fazer com todo o espécime axilar contendo 15 ou mais linfonodos (Turner et al., 1997).

O primeiro estudo sobre o exame citológico no ato intra-operatório para avaliação dos linfonodos axilares demonstrou acurácia de $100 \%$ em relação ao exame histológico (Rimsten et al., 1974), e, desde então, numerosos estudos têm demonstrado alto valor preditivo e acurácia próxima de $99 \%$ em relação aos exames histológicos pós-operatórios associados ou não ao exame imuno-histoquímico para o diagnóstico de micrometástases (Rubio et al., 1998; Klimberg et al., 2002; Ratanawichtrasin et al., 1999).

Nasser et al., 1993 estudaram 159 pacientes com câncer de mama com linfonodos axilares livres de metástases e encontraram 50 pacientes (31\%) com metástases em linfonodos axilares menores que $0,2 \mathrm{~mm}$ ou detectadas somente ao exame imuno-histoquímico. As pacientes com essas metástases ocultas não mostraram diferença na taxa de sobrevivência quando comparadas às pacientes com linfonodos negativos. Entretanto, as pacientes com metástases maiores que 0,2 mm tiveram maior índice de recidiva e menor taxa geral de sobrevivência.

Embora não haja ainda consenso quanto ao significado biológico de micrometástases menores ou maiores que $0,2 \mathrm{~mm}$, o achado de metástases ocultas aumentou sensivelmente com o emprego cada vez mais freqüente do estudo do LS, o que permite que a estrutura representativa do estado 
linfonodal axilar seja estudada com maior rigor nos cortes seriados em estudos imuno-histoquímicos. O significado biológico provavelmente depende do tamanho dessas micrometástases, da localização do linfonodo, das características das células, além de outros fatores relacionados à paciente e ao tumor primário.

Hartveit \& Lilleng, 1996 estudaram 138 pacientes com câncer de mama submetidas à linfadenectomia axilar e que apresentavam apenas micrometástase axilar única. Observaram que metástases no tecido linfóide se associam a prognóstico melhor que o daquelas localizadas nos linfáticos capsulares e no seio subcapsular. Outra possibilidade aventada foi a de que as metástases ocultas não representariam a evolução natural do câncer de mama, mas decorreriam da possibilidade de que alguns desses focos fossem de origem traumática, especialmente decorrente de massagens que são aplicadas nas mamas após a injeção do radiofármaco ou de corantes (Rosser, 2000).

Turner et al., 1997 relataram que 64 de 157 LS negativos pela técnica de hematoxilina-eosina tiveram metástases identificadas por exame imunohistoquímico. Por outro lado, nas 60 pacientes cujos LS eram negativos tanto pela hematoxilina-eosina quanto pelo exame imuno-histoquímico, a análise imuno-histoquímica de 1087 linfonodos não-sentinelas revelou apenas um linfonodo com metástase. A ausência de micrometástase em linfonodos não-sentinelas é promissora, pois ameniza a idéia de que a doença micrometastática não removida cirurgicamente pode resultar em alta incidência de recorrência local ou em impacto negativo na sobrevida. 
Hartveit \& Lilleng, 1996 observaram que as micrometástases no seio subcapsular não alteram o prognóstico, enquanto que, no tecido linfonodal, estão associadas a menor sobrevida. Outros autores (Lockett et al., 1998; Mori et al., 1995) relataram o uso de PCR (reação em cadeia da polimerase) para identificar RNA de células malignas em linfonodos axilares, com achados positivos em $30 \%$ a $40 \%$ dos casos. O significado clínico desses achados ainda é completamente desconhecido.

Vislumbra-se possibilidade futura de muitas pacientes com LS positivos poderem permanecer com os linfonodos axilares restantes. Quando o LS é positivo, a positividade dos linfonodos axilares restantes é de aproximadamente 50\% (Veronesi et al., 1997; Cox et al., 2000; Krag et al., 1998). Vários estudiosos neste assunto têm pesquisado fatores que possam autorizar a conservação dos linfonodos axilares restantes na outra metade de pacientes que apresentam apenas o LS comprometido por metástases. Entre esses fatores estão o tamanho do tumor primário (menor que $1 \mathrm{~cm}$ ), o tamanho da metástase no LS (menor que 0,2 cm), o número de LS metastáticos (um), e a ausência de invasão angiolinfática peritumoral (Abdessalan et al., 2001; Kamath et al., 2001; Rahusen et al., 2001).

Mesmo depois de todos esses estudos terem demonstrado que o estado do LS constitui preditor preciso dos linfonodos axilares em câncer de mama, ainda é necessária a conclusão do estudo com cortes seriados coloridos pela hematoxilina-eosina e com exame imuno-histoquímico, para meIhor planejar a conduta, sobretudo quanto ao tratamento cirúrgico locorregional. 


\subsection{Justificativa}

A quimioterapia neoadjuvante é o tratamento quimioterápico realizado em pacientes com carcinoma de mama localmente avançado antes do procedimento cirúrgico. A finalidade da quimioterapia neoadjuvante é reduzir a dimensão tumoral de forma a possibilitar intervenção cirúrgica conservadora, ou seja, quadrantectomia e esvaziamento axilar sem lançar mão da mastectomia radical. Esta última, além do caráter mutililador, traz, com muita frequência, graves conseqüências psicológicas e tem alto custo para o Sistema de Saúde, pois exige reconstrução do órgão extirpado.

Uma estratégia lógica para a "performance" da quimioterapia neoadjuvante seria a injeção locoregional direta do quimioterápico, que propiciaria maior concentração do quimioterápico no sítio de ação. No entanto, devido ao possível efeito necrosante do quimioterápico nos tecidos sadios circunjacentes ao tumor e a validade desta via em termos dos mecanismos de ação e captação celular do fármaco.

Como vimos, ao envolver o quimioterápico no interior de sua estrutura, as nanopartículas de LDE evitam seu contato direto com os tecidos normais e propiciam um mecanismo de captação e entrada na célula através da endocitose mediada por receptor. Isto posto, nos defrontamos com a hipótese atraente de utilizar o sistema LDE, que tem sido empregado nos estudos apenas em administração sistêmica, para possibilitar o emprego da técnica de injeção locorreginal de quimioterápicos na quimioterapia neoadjuvante. 
Para tanto, é necessário inicialmente encontrar a técnica mais adequada de injeção local da nanoemulsão do ponto de vista de sua concentração nos sítios-alvo, a saber, o próprio tumor e o linfonodo axilar. 


\section{OBJ ETVOS}

1. Verificar em pacientes com carcinoma de mama a concentração da LDE no tecido tumoral, no tecido mamário normal e no linfonodo axilar após três técnicas diferentes de injeção locorregional:
a) injeção no tecido mamário normal a $5 \mathrm{~cm}$ de distância do tumor.
b) injeção peritumoral.
c) injeção intratumoral.
2. Determinar a cinética plasmática da LDE após a injeção efetuada através das três diferentes técnicas. 


\section{METODOLOGIA}

\subsection{Casuística}

Foram selecionadas 14 pacientes voluntárias do Hospital São Joaquim da Real e Benemérita Associação Portuguesa de Beneficência, todas com carcinoma invasivo de mama em estádios clínicos I, II e III (TNM, L’Union Internationale Contre le Cancer - UICC). O diagnóstico foi confirmado por biópsia percutânea por agulha grossa, unifocal, pela mamografia e/ou por ultra-som de mama.

Todas as participantes estavam programadas para tratamento cirúrgico do tumor de mama e pesquisa do linfonodo sentinela, seguida de esvaziamento axilar, com ou sem evidência clínica e/ou imaginológica de comprometimento de linfonodo axilar ipsilateral (N0) (N1) (N2).

\subsubsection{Critérios de inclusão}

Os critérios adotados para a inclusão das pacientes neste estudo foram os seguintes:

1) Idade superior a 18 anos .

2) Diagnóstico histológico de carcinoma invasivo de mama. 
3) Tumores classificados em estádios clínicos I, II , IIIA, IIIB e IIIC.

4) Tumores unilaterais ou bilaterais unifocais.

5) Resultados considerados dentro dos limites de referência para normalidade para os exames hematológicos, provas de função renal e hepática e perfil lipídico.

6) Pacientes que assinaram Termo de Consentimento Livre e Esclarecido (Anexo $A$ )

\subsubsection{Critérios de exclusão}

Foram estabelecidos os seguintes critérios de exclusão.

1) Gravidez ou lactação até um ano após o parto.

2) Carcinoma metacrônico de mama.

3) Carcinoma do tipo inflamatório.

4) Tumor multicêntrico.

5) Cirurgia ou radioterapia prévia na axila ipsilateral.

\subsubsection{Caracterização do grupo de estudo}

Os dados descritivos individuais das pacientes deste estudo, incluindo os tipos de cirurgia a que foram submetidas, são apresentados na Tabela 1. Dados relativos ao diagnóstico anatomopatológico (tipo e grau histológico), aos estadiamentos cirúrgico e clínico da doença, aos resultados da análise imuno-histoquímica e ao peso e dimensão da mama e tumor são apresenta- 


\section{dos na Tabela 2.}

TABELA 1. idade das pacientes e tipo de cirurgia realizadas

\begin{tabular}{lcl}
\hline Paciente & Idade & Tipo de cirurgia \\
\hline 1 & 46 & Mastectomia radical modificada a Maden \\
2 & 87 & Mastectomia radical modificada a Maden \\
3 & 67 & Quadrantectomia com esvaziamento axilar \\
4 & 74 & Quadrantectomia com esvaziamento axilar \\
5 & 57 & Mastectomia radical modificada a Maden \\
6 & 48 & Mastectomia radical modificada a Maden \\
7 & 60 & Mastectomia radical modificada a Maden \\
8 & 38 & Quadrantectomia com esvaziamento axilar \\
9 & 61 & Quadrantectomia com esvaziamento axilar \\
10 & 49 & Quadrantectomia com esvaziamento axilar \\
11 & 63 & Mastectomia radical modificada a Maden \\
12 & 67 & Mastectomia radical modificada a Maden \\
13 & 53 & Mastectomia radical modificada a Maden \\
14 & 42 & Quadrantectomia com esvaziamento axilar \\
\hline
\end{tabular}

TABELA 2. Dados do diagnóstico anatomopatológico, estadiamentos cirúrgico e clínico da doença e resultados da análise imuno-histoquímica nas 14 pacientes incluídas no estudo

\begin{tabular}{|c|c|c|c|c|c|c|c|c|c|c|}
\hline & \multicolumn{2}{|c|}{ Histologia } & \multicolumn{2}{|l|}{ Estadiamentos } & \multicolumn{2}{|c|}{$\begin{array}{l}\text { Análise imuno- } \\
\text { histoquímica }\end{array}$} & \multirow{2}{*}{$\begin{array}{l}\text { Peso } \\
\text { mama } \\
(g)\end{array}$} & \multirow[t]{2}{*}{$\begin{array}{l}\text { Medidas } \\
\text { tumor }(\mathrm{cm})\end{array}$} & \multirow{2}{*}{$\begin{array}{l}\text { Peso } \\
\text { tu- } \\
\text { mor } \\
(g)\end{array}$} & \multirow{2}{*}{$\begin{array}{l}\text { Propor- } \\
\text { ção tu- } \\
\text { morl } \\
\text { mama } \\
(\%)\end{array}$} \\
\hline & Tipo & Grau & Cirúrgico & Clínico & REP & HER-2 & & & & \\
\hline 1 & CDI & G3 & pT3p N1 M0 & IIIA & - & - & 530 & $5,5 \times 8,0 \times 3,5$ & 84,8 & $16,0 \%$ \\
\hline 2 & CDI & G2 & pT1c pNo M0 & I & + & - & 180 & $1,4 \times 1,2 \times 1,0$ & 3,1 & $1,7 \%$ \\
\hline 3 & CDI & $\mathrm{G} 2$ & pT1c N2 M0 & IIIA & + & + & $456^{*}$ & $1,6 \times 1,4 \times 0,7$ & 7,3 & $1,6 \%$ \\
\hline 4 & CDI & G3 & pT2p NO MO & IIA & + & - & $668^{*}$ & $2,5 \times 1,6 \times 1,0$ & 26,7 & $4,0 \%$ \\
\hline 5 & CDI & G3 & pT1c pN3 M0 & IIIC & + & + & 675 & $1,5 \times 1,2 \times 1,0$ & 12,2 & $1,8 \%$ \\
\hline 6 & CLI & G2 & pT1c pNO MO & I & + & - & 350 & $1,4 \times 1,0 \times 0,5$ & 4,2 & $1,2 \%$ \\
\hline 7 & CDI & G3 & pT2 pNO MO & IIA & - & + & 705 & $3,0 \times 2,0 \times 1,0$ & 31,7 & $4,5 \%$ \\
\hline 8 & $\mathrm{CM}$ & - & pT1c pNO MO & I & - & - & $344^{*}$ & $1,9 \times 1,2 \times 0,8$ & 7,9 & $2,3 \%$ \\
\hline 9 & CDI & G3 & pT1c pNO MO & I & + & - & $368^{*}$ & $2,0 \times 1,5 \times 1,0$ & 11,0 & $3,0 \%$ \\
\hline 10 & CDI & $\mathrm{G} 2$ & pT2 pN1 M0 & IIB & + & - & $512^{*}$ & $2,1 \times 1,3 \times 1,0$ & 13,8 & $2,7 \%$ \\
\hline 11 & CDI & $\mathrm{G} 2$ & pT2 pN3 M0 & IIIC & + & - & 544 & $4,0 \times 3,5 \times 2,5$ & 114,2 & $21,0 \%$ \\
\hline 12 & CLI & $\mathrm{G} 2$ & pT1c pN1 miM0 & $\| \mathrm{A}$ & + & - & 570 & $1,9 \times 1,7 \times 0,6$ & 45,6 & $8,0 \%$ \\
\hline 13 & CDI & $\mathrm{G} 2$ & pT2 pN1 M0 & IIB & + & - & 294 & $4,2 \times 2,5 \times 1,0$ & 29,4 & $10,0 \%$ \\
\hline 14 & CDI & G3 & pT1c pNo Mx & I & + & - & $640^{*}$ & $1,8 \times 1,0 \times 0,5$ & 11,5 & $1,8 \%$ \\
\hline
\end{tabular}

CDI: Carcinoma ductal invasivo; CLI: Carcinoma lobular infiltrativo; CM: Carcinoma medular. REP: Receptor de estrógeno e progesterona. +: Positivo; -: Negativo; $\left({ }^{*}\right)$ Resultados da multiplicação por 4 do peso da peça obtida em quadrantectomia.

\section{Este estudo foi aprovado pela Comissão de Ética para Análise de Pro-} jetos de Pesquisa (CAPPesq) do Hospital das Clínicas da Faculdade de Me- 
dicina da Universidade de São Paulo (HCFMUSP) e pelo Comitê de Ética e Pesquisa do Hospital Beneficência Portuguesa (CEPesq 334/06) (Anexos B e C).

\subsection{Protocolo experimental}

Em todas as pacientes do estudo foram realizados os seguintes exames antes da cirurgia: mamografia bilateral, ultrassonografia das mamas, raios- $x$ de tórax nas incidências perfil esquerdo e póstero-anterior e ultrassonografia pélvica e abdominal.

A LDE com marcação radioativa, preparada conforme a técnica descrita abaixo, foi injetada previamente à cirurgia. Após a injeção da LDE, foram colhidas amostras de sangue de todas as pacientes, em intervalos predeterminados durante o período de 24 horas para obtenção da curva de decaimento plasmático da nanoemulsão.

As pacientes foram alocadas em três grupos distintos, de acordo com diferentes locais de injeção da LDE, a saber:

1) Grupo 1 (G1): quatro pacientes (números 4, 5, 7 e 8) receberam injeção da LDE no parênquima mamário, a $5 \mathrm{~cm}$ da borda da lesão, 12 horas antes do ato cirúrgico.

2) Grupo 2 (G2): quatro pacientes (números 1, 2, 3 e 6) receberam injeção peritumoral da LDE, 12 horas antes do ato cirúrgico.

3) Grupo 3 (G3): seis pacientes (números 9, 10, 11, 12, 13 e 14) receberam injeção intralesional da LDE. Este grupo foi subdividido em dois: 
- Grupo 3a (G3a): em quatro pacientes (números 9, 10, 11 e 12) a LDE foi injetada 2 horas antes da cirurgia.

- Grupo 3b (G3b): em duas pacientes (números 13 e 14) a LDE foi injetada 12 horas antes da cirurgia.

No início do ato operatório, foram injetados $2 \mathrm{ml}$ do corante azul patente V (sal sódico, $50 \mathrm{mg} / \mathrm{ml}$ ) na região periareolar da mama comprometida pela neoplasia, com vistas a evidenciar o linfonodo sentinela na região axilar, o que é possível cinco minutos após a injeção do corante.

As pacientes foram submetidas a mastectomia total modificada com preservação do músculo pequeno peitoral (técnica de Auchincloss e Madden) ou a quadrantectomia. A quadrantectomia foi adotada mediante delimitação das margens e confirmação do seu não comprometimento por células neoplásicas observado pelo exame anatomopatológico in loco.

A pesquisa do linfonodo sentinela foi realizada em todas as pacientes, e todos os linfonodos sentinela corados pelo azul patente foram extirpados e recebidos a fresco pelo patologista que procedeu à avaliação citológica intraoperatória. A seguir foram seccionados transversalmente a intervalos de $0,2 \mathrm{~mm}$, examinados macroscopicamente e submetidos à citologia por contato de todas as superfícies de corte. Os esfregaços foram corados pela técnica rápida da hematoxilina-eosina (um minuto em hematoxilina em água corrente e 20 segundos em eosina em álcool absoluto) e estudados em microscopia óptica com aumento de 40 vezes. O exame anatomopatológico com base nesta avaliação indicou linfonodo(s) negativo(s) ou positivo(s) para células neoplásicas. 
Quando o linfonodo sentinela se mostrou positivo para metástase tumoral, procedeu-se ao esvaziamento axilar nos três níveis para pesquisa dos linfonodos axilares.

Todos os linfonodos foram recebidos a fresco pelo patologista e estudados tanto por macroscopia quanto por citologia; os comprometidos por invasão carcinomatosa foram processados para a quantificação da captação da LDE.

As pacientes em que a pesquisa do linfonodo sentinela se mostrou negativa para comprometimento metastático por carcinoma de mama tiveram os linfonodos do nível 1 axilar extirpados, e selecionou-se um linfonodo para determinação da captação da LDE marcada radioativamente.

Em todos os casos o tumor primário foi identificado na peça cirúrgica e seccionado, retirando-se um fragmento do centro do tumor que foi encaminhado para ser processado para análise da captação de LDE marcada. Tomou-se o cuidado de haver somente tecido neoplásico, evitando-se utilizar a periferia do tumor devido a processo inflamatório local ou áreas de necrose tumoral.

\subsubsection{Determinações plasmáticas do perfil lipídico}

O perfil lipídico das pacientes foi determinado previamente à cirurgia com as pacientes em jejum de 12 horas. Para tanto, foram colhidos $5 \mathrm{ml}$ de sangue em tubo seco, por meio de punção de veia periférica, 12 horas antes da cirurgia nas 14 pacientes. 
As determinações de triglicérides e de colesterol total foram realizadas pelo método colorimétrico, utilizando-se, respectivamente, os kits comerciais GPO/PAP e o Colesterol CHOD-PAP, ambos da Roche® (Basiléia, Suíça). Foram adotados valores normais de referência para os triglicérides $\leq 200 \mathrm{mg} / \mathrm{dl}$ e para o colesterol até $200 \mathrm{mg} / \mathrm{dl}$. A medida do colesterol da HDL foi realizada por precipitação das lipoproteínas contendo a apolipoproteína B (LDL e VLDL) do plasma total, pela adição do reativo ácido fosfotúngstico e dos íons de magnésio, seguida da centrifugação do plasma a 3.500 rotações por minuto (rpm) durante um quarto de hora, momento em que se obtinha a HDL no sobrenadante. Esta avaliação foi realizada por método enzimático com uso do kit CHOD-PAP da Roche ${ }^{\circledR}$ (Basiléia, Suíça), cujo valor de normalidade é $\geq 45 \mathrm{mg} / \mathrm{dl}$. A determinação do colesterol da LDL foi obtida pela aplicação da fórmula de Friedewald et al., 1972:

$\mathrm{LDL}=$ colesterol total $-(\mathrm{VLDL}+\mathrm{HDL})$

O valor da VLDL foi obtido pela divisão dos valores dos triglicérides por cinco, quando inferiores a $400 \mathrm{mg} / \mathrm{dl}$. O valor considerado normal da VLDL foi $\leq 40 \mathrm{mg} / \mathrm{dl}$.

Os valores de colesterol total e frações e triglicérides das pacientes estudadas estão apresentados na Tabela 3. 
TABELA 3. Concentrações (em mg/dl) de triglicérides, colesterol total e frações em sangue coletado 12 horas antes da cirurgia nas 14 pacientes no estudo

\begin{tabular}{lccccc}
\hline Paciente & Triglicérides & Colesterol total & HDL & LDL & VLDL \\
\hline 1 & & & & & \\
2 & 79 & 143 & 39 & 101 & 3 \\
3 & 89 & 146 & 53 & 64 & 29 \\
4 & 146 & 224 & 69 & 127 & 42 \\
5 & 61 & 210 & 56 & 107 & 47 \\
6 & 142 & 165 & 48 & 89 & 12 \\
7 & 62 & 191 & 48 & 131 & 12 \\
8 & 161 & 178 & 35 & 11 & 32 \\
9 & 113 & 169 & 41 & 116 & 12 \\
10 & 109 & 207 & 56 & 129 & 12 \\
11 & 51 & 146 & 42 & 94 & 10 \\
12 & 223 & 355 & 75 & 235 & 45 \\
13 & 69 & 218 & 51 & 153 & 14 \\
14 & 50 & 208 & 74 & 104 & 30 \\
& 61 & 122 & 52 & 61 & 9 \\
\hline Média & $\mathbf{1 0 1}$ & $\mathbf{1 9 1}$ & $\mathbf{5 2}$ & $\mathbf{1 0 8}$ & $\mathbf{2 2}$ \\
Desvio-padrão & $\mathbf{4 9}$ & $\mathbf{5 4}$ & $\mathbf{1 2}$ & $\mathbf{4 9}$ & $\mathbf{1 4}$ \\
\hline
\end{tabular}

Legenda:

HDL: High Density Lipoprotein;

LDL: Low Density Lipoprotein;

VLDL: Very Low Density Lipoprotein.

Valores de referência:

Triglicérides: <201 mg/dl;

Colesterol total: $<200 \mathrm{mg} / \mathrm{dl}$;

HDL: $>44 \mathrm{mg} / \mathrm{dl}$;

LDL: $<130 \mathrm{mg} / \mathrm{dl}$;

VLDL: $<40 \mathrm{mg} / \mathrm{dl}$.

\subsubsection{Preparo da LDE}

A emulsão LDE foi preparada a partir da mistura de lipídeos compostos de $40 \mathrm{mg}$ de fosfatidilcolina, $20 \mathrm{mg}$ de oleato de colesterol (marcado com trício), $1 \mathrm{mg}$ de trioleína e $0,5 \mathrm{mg}$ de colesterol livre. A emulsificação dos lipídeos e a purificação da emulsão foram realizadas de acordo com o procedimento descrito por Ginsburg et al., 1982 e modificado por Maranhão et al,. 1994. A fosfatidilcolina, a trioleína e o colesterol livre utilizados no preparo da emulsão foram obtidos da Sigma® (St. Louis, EUA). O oleato de colesterol marcado com trício foi adquirido da Amersham ${ }^{\circledR}$ (Little Chalfont, Grã- 
Bretanha). Estes lipídeos têm grau de pureza de 98\%, confirmado por cromatografia de camada delgada.

Os lipídeos foram dissolvidos em clorofórmio/metanol (2:1) e colocados em frascos. O oleato de colesterol marcado com trício foi acrescentado aos frascos. A mistura foi seca sob nitrogênio e, em seguida, por dissecação a vácuo durante toda a noite a $4^{\circ} \mathrm{C}$, com a finalidade de remover solventes residuais.

Os lipídeos secos foram postos novamente em suspensão em 10ml de 0,01 M-tris-Ácido Clorídrico $(\mathrm{HCl})$ ao $\mathrm{pH}$ de 8,0, e a temperatura mantida acima de $52^{\circ} \mathrm{C}$, com a finalidade de manter o oleato de colesterol acima do seu ponto de fusão, monitorizando os tubos durante todo o procedimento. A emulsão lipídica em suspensão foi então transferida para tubos limpos na ultracentrífuga Beckman XL-100K, a 36.000 rpm, durante 30 minutos, a $4^{\circ} \mathrm{C}$.

A parte superior da solução conteve partículas que flutuaram à densidade de aproximadamente $1,006 \mathrm{~g} / \mathrm{ml}$, as quais foram removidas por aspiração com agulha. A solução remanescente foi ajustada à densidade de 1,21 $\mathrm{g} / \mathrm{ml}$ por acréscimo de brometo de potássio (KBr) sólido. Realizou-se, então, o segundo passo da ultracentrifugação a 36.000 rpm, por 120 minutos, a $4^{\circ} \mathrm{C}$. Retiraram-se $20 \%$ a $30 \%$ da porção superior da amostra por aspiração, após igualar-se à temperatura ambiente. A solução foi submetida à diálise durante toda a noite em solução tampão com pH 8,0 a 10 mM Tris$\mathrm{HCl}$, para remoção do $\mathrm{KBr}$. Esta fração da LDE foi esterilizada por passagem através de filtro com microporos de $0,22 \mu$.

A LDE pode ser utilizada até quatro semanas depois do seu preparo, e 
a porcentagem molar de sua composição é constituída de $48 \%$ de ésteres de colesterol (oleato de colesterol), $47,8 \%$ de fosfolipídios (fosfatidilcolina), 2,3\% de triglicérides (trioleína) e 1,9\% de colesterol livre não esterificado.

\subsubsection{Determinação da cinética plasmática da LDE}

As amostras de sangue foram colhidas 5 minutos, 1, 2, 4, 6, 8, 12, e 24 horas após a injeção da emulsão marcada, com o objetivo de se obter uma curva de decaimento plasmático da LDE. Este procedimento foi realizado em quatorze pacientes.

Foram colhidos $5 \mathrm{ml}$ de sangue em tubo contendo heparina, que foi imediatamente enviado para o Laboratório de Lípides do INCOR-HCFMUSP para a determinação de sua radioatividade em contagens por minutos por mililitros de plasma $(\mathrm{cpm} / \mathrm{ml})$ do oleato de colesterol triciado.

O sangue foi submetido à centrifugação de $3.000 \mathrm{rpm}$, durante $15 \mathrm{mi}-$ nutos. Um mililitro de plasma foi retirado e adicionado em $7 \mathrm{ml}$ de solução cintiladora (PPO / POPOP / Triton-X-100 / tolueno, 5g/ 0,5g /333ml/ 667ml), utilizando-se contador Beta (Packard, modelo 1660 TR, EUA).

\subsubsection{Coleta do material}

Durante o ato cirúrgico, fragmentos de tecido tumoral, de tecido mamário normal, de linfonodos comprometidos por metástase e de linfonodos livres de neoplasia com aproximadamente $1 \mathrm{~cm}^{3}$ foram acondicionados em 
tubos de ensaio estéreis, com solução fisiológica gelada (cloreto de sódio a $0,9 \%$, entre $5^{\circ} \mathrm{C}$ e $8^{\circ} \mathrm{C}$ ) e encaminhados ao Laboratório de Lípides do INCOR-HCFMUSP para processamento e medida da radioatividade. O produto restante da mastectomia e do esvaziamento axilar foi enviado para o Setor da Anatomia Patológica do Hospital São Joaquim.

\subsubsection{Contagem da radioatividade nas peças cirúrgicas}

Cada fragmento de tecido foi processado separadamente. Cerca de 1,0g foi extraído do fragmento na parte sólida da amostra e, então, macerado manualmente até adquirir consistência pastosa. A seguir, foi transferido para tubos de ensaio nos quais foram adicionados $10 \mathrm{ml}$ de metanol e $20 \mathrm{ml}$ de clorofórmio. Após 12 horas a $4^{\circ} \mathrm{C}$, a mistura foi passada por papel de filtro, adicionando-se $5,0 \mathrm{ml}$ de clorofórmio e 7,0ml de água bidestilada. Após 12 horas a $4^{\circ} \mathrm{C}$, foram aspirados $4 \mathrm{ml}$ de sobrenadante que foram descartados. À mistura restante foram adicionados $4 \mathrm{ml}$ de Clear Folch (clorofórmio / metanol / água bidestilada, 3/48/47). Após mais 12 horas a $4^{\circ} \mathrm{C}$, foi aspirada e descartada a fase sobrenadante.

A amostra resultante foi seca sob fluxo de nitrogênio, ressuspendida com clorofórmio e metanol 2:1 e submetida à cromatografia em camadas delgadas, com aplicação em placas de silicagel $60 \mathrm{H}$ (Merck®). O solvente utilizado para migração das frações lipídicas foi hexano / éter etílico / ácido acético, 70/30/1ml. A radioatividade presente na fração do oleato de colesterol foi medida em 7,0ml de solução cintiladora (PPO / POPOP / Triton-X-100 
/ tolueno, $5 \mathrm{~g} /$ 0,5g / 333ml / 667ml), utilizando-se contador Beta (Packard, modelo 1660 TR, EUA).

A radioatividade obtida da fração oleato de colesterol triciado das amostras dos tecidos (tumor, glândula mamária e linfonodo) foi dada em contagens por minuto por grama de tecido $(\mathrm{cpm} / \mathrm{g})$.

\subsection{Análise estatística}

As médias e desvios-padrão dos valores de captação da LDE expressos em cpm/g foram comparados entre os grupos de estudo e, em cada grupo, entre os locais de captação (tecido normal, tumoral e linfonodo axilar), com o emprego de ANOVA Kruskal-Wallis não paramérica para análise multivariada, e da Prova de Mann-Whitney para comparações emparelhadas. Eventuais correlações foram examinadas com o Quociente de Correlação de Spearman. Adotou-se nível de significância de 95\% ( $p \leq 0,05)$. 


\section{RESULTADOS}

$\mathrm{Na}$ Tabela 4 estão os valores de captação de LDE pelo tecido tumoral, tecido mamário e pelos linfonodos obtidos nos três grupos de estudo, expressos em cpm por grama de tecido (cpm/g). Observa-se grande variação nos valores de captação de uma paciente para outra no mesmo grupo de estudo.

TABELA 4. Captação de LDE em cpm/g de tecido normal de mama, tecido tumoral, e lifonodo axilar nas 14 pacientes divididas em grupos, de acordo com o local da injeção

\begin{tabular}{|c|c|c|c|c|c|}
\hline Grupos & Pacientes & $\begin{array}{c}\text { Tecido } \\
\text { normal da } \\
\text { mama }\end{array}$ & $\begin{array}{l}\text { Tecido tumoral } \\
\text { da mama }\end{array}$ & $\begin{array}{l}\text { Linfonodo } \\
\text { axilar }\end{array}$ & $\begin{array}{l}\text { Valor } \\
\text { de } p \\
\text { (Kruskal- } \\
\text { Wallis) }\end{array}$ \\
\hline \multirow[t]{2}{*}{ G1 } & 4 & 117 & 159 & 822 & \multirow{5}{*}{$\begin{array}{c}\mathrm{H}= \\
1,42 \\
p= \\
0,4916\end{array}$} \\
\hline & 5 & 239 & 50 & $19^{*}$ & \\
\hline \multirow{3}{*}{$\begin{array}{l}\text { (Injeção } \\
\text { intramamária } \\
\text { da LDE) }\end{array}$} & 7 & 6 & 8 & 138 & \\
\hline & 8 & 196 & 7 & 78 & \\
\hline & Média $\pm D P$ & $139 \pm 102$ & $60 \pm 71$ & $263 \pm 375$ & \\
\hline \multirow[t]{2}{*}{$\mathrm{G} 2$} & 1 & 1 & 40 & $189^{*}$ & \multirow{5}{*}{$\begin{array}{c}H= \\
3,00 \\
p= \\
0,2231\end{array}$} \\
\hline & 2 & 838 & 3.133 & 9 & \\
\hline \multirow{3}{*}{$\begin{array}{l}\text { (Injeção } \\
\text { peritumoral } \\
\text { da LDE) }\end{array}$} & 3 & 24 & 122 & $103^{*}$ & \\
\hline & 6 & 7 & 79 & 107 & \\
\hline & Média $\pm D P$ & $217 \pm 413$ & $843 \pm 1.526$ & $102 \pm 74$ & \\
\hline \multirow[t]{2}{*}{ G3 } & 9 & 62 & 99.948 & 436 & \multirow{7}{*}{$\begin{array}{c}H= \\
13,13 \\
p= \\
0,0014\end{array}$} \\
\hline & 10 & 37 & 126.136 & 16 & \\
\hline (Injeção & 11 & 92 & 4.100 & $18^{*}$ & \\
\hline Intratumoral & 12 & 561 & 1.561 & $1.409^{*}$ & \\
\hline \multirow[t]{3}{*}{ da LDE) } & 13ల & 4.236 & 4.042 & $6.148^{*}$ & \\
\hline & $14 \pi$ & 76 & 32.824 & 6.112 & \\
\hline & Média $\pm D P$ & $844 \pm 1.673$ & $44.769 \pm 5.4749$ & $2.356 \pm 2966$ & \\
\hline
\end{tabular}

G1: Injeção da LDE no parênquima mamário (a $5 \mathrm{~cm}$ da lesão) 12 horas antes do ato cirúrgico.

G2: Injeção da LDE na região peritumoral 12 horas antes do ato cirúrgico.

G3: Injeção da LDE intralesional duas horas (4 pacientes) ou 12 horas (2 pacientes, $n^{\circ \text { s }}$. 13 e 14 , marcados com T) antes do ato cirúrgico.

$\left({ }^{*}\right)$ : Linfonodos comprometidos. 
No G1, no qual a LDE foi injetada no tecido mamário a $5 \mathrm{~cm}$ do tumor, a captação pelo tecido tumoral não foi estatisticamente diferente da captação pelo tecido mamário normal, embora a média de captação tenha sido cerca de duas vezes menor no tecido tumoral do que no normal.

No G2, no qual foi realizada injeção peritumoral de LDE, tampouco houve diferença estatística entre a captação pelo tecido tumoral e pelo normal. No entanto, a média de captação pelo tecido tumoral foi cerca de quatro vezes maior do que pelo tecido mamário normal, em contraste ao que ocorreu no G1.

No G3, no qual a LDE foi injetada intralesional, a captação dessa nanoemulsão foi significativamente maior no tecido tumoral do que no tecido mamário normal $(U=1 ; p=0,002)$. A média de captação, neste grupo, foi 53 vezes maior no tumor do que na parte normal da mama.

Quando se comparam os três grupos quanto à captação da LDE pelo tecido tumoral, foi marcante a diferença de captação entre o G3 e os outros dois grupos de estudo $(U=0 ; p=0,005$ e $U=1 ; p=0,010$, respectivamente para G1 e G2). A média de captação tumoral obtida no G3 foi 765 vezes maior do que a captação tumoral obtida no $\mathrm{G} 1$ e 36 vezes maior do que a do G2.

No tocante ao tecido mamário normal, no G3 a captação da LDE foi estatisticamente igual à do G2 e do G1. Embora a média dos valores determinada em G3 tenha sido cerca de 16 vezes maior do que em G1 e quatro vezes maior do que em G2, a variação inter-individual dos valores de captação foi muito grande. 
Na Tabela 4 também estão os valores de captação da LDE pelos linfonodos. Em todos os três grupos de estudo não houve diferença entre a captação de LDE pelos linfonodos e pelo tecido mamário normal, observando-se grande variação inter-individual nos valores de captação.

Na Tabela 5 estão discriminados os valores de captação da LDE obtidos dos linfonodos comprometidos e nos não-comprometidos pelo processo neoplásico.

TABELA 5. Captação de LDE em cpm/g pelos linfonodos comprometidos e não comprometidos nas 14 pacientes incluídas no estudo divididas em grupos, de acordo com o local da injeção de LDE

\begin{tabular}{llccc}
\hline Grupos & Valores & \multicolumn{2}{c}{ Linfonodos } & Valor de \\
& encontrados & Comprometidos & Não comprometidos & $p$ \\
G1 & Média $\pm D P$ & - & $346 \pm 413$ & - \\
G2 & Média $\pm D P$ & $146 \pm 60$ & $58 \pm 69$ & 0,9170 \\
G3 & Média $\pm D P$ & $2.525 \pm 3.213$ & $2.188 \pm 3.404$ & 0,9067 \\
\hline
\end{tabular}

G1: LDE peritumoral 12 horas antes do ato cirúrgico.

G2: LDE no parênquima mamário (a $5 \mathrm{~cm}$ da lesão) 12 horas antes do ato cirúrgico.

G3: LDE intralesionall duas horas (quatro pacientes) ou 12 horas (duas pacientes) antes do ato cirúrgico.

A amostragem pequena impossibilitou a análise estatística no G1, já que havia apenas um caso com linfonodo comprometido. No tocante ao G2 e ao G3, não houve diferença significativa na captação por linfonodos comprometidos e não comprometidos.

Na Tabela 4 fica evidente que, no G3, a captação da LDE pelos linfonodos tanto comprometidos quanto não comprometidos foi significativamente maior que no $G 1(U=2 ; p=0,019)$ e no $G 2(U=3 ; p=0,033)$.

Na Figura 1 estão representadas as curvas de aparecimento e desaparecimento do marcador radioativo da LDE no plasma. As curvas de G1 e G2 
são parecidas, com aumento gradativo da radioatividade no plasma do ponto de coleta de sangue inicial até o tempo de 12 horas, quando atinge o pico a partir do qual passa a desaparecer do compartimento plasmático. Já a curva de G3 é nitidamente diferente. No ponto inicial de coleta já há quantidade apreciável de radioatividade que é mantida estável até o tempo de 8 horas de observação, a partir do qual passa a declinar.
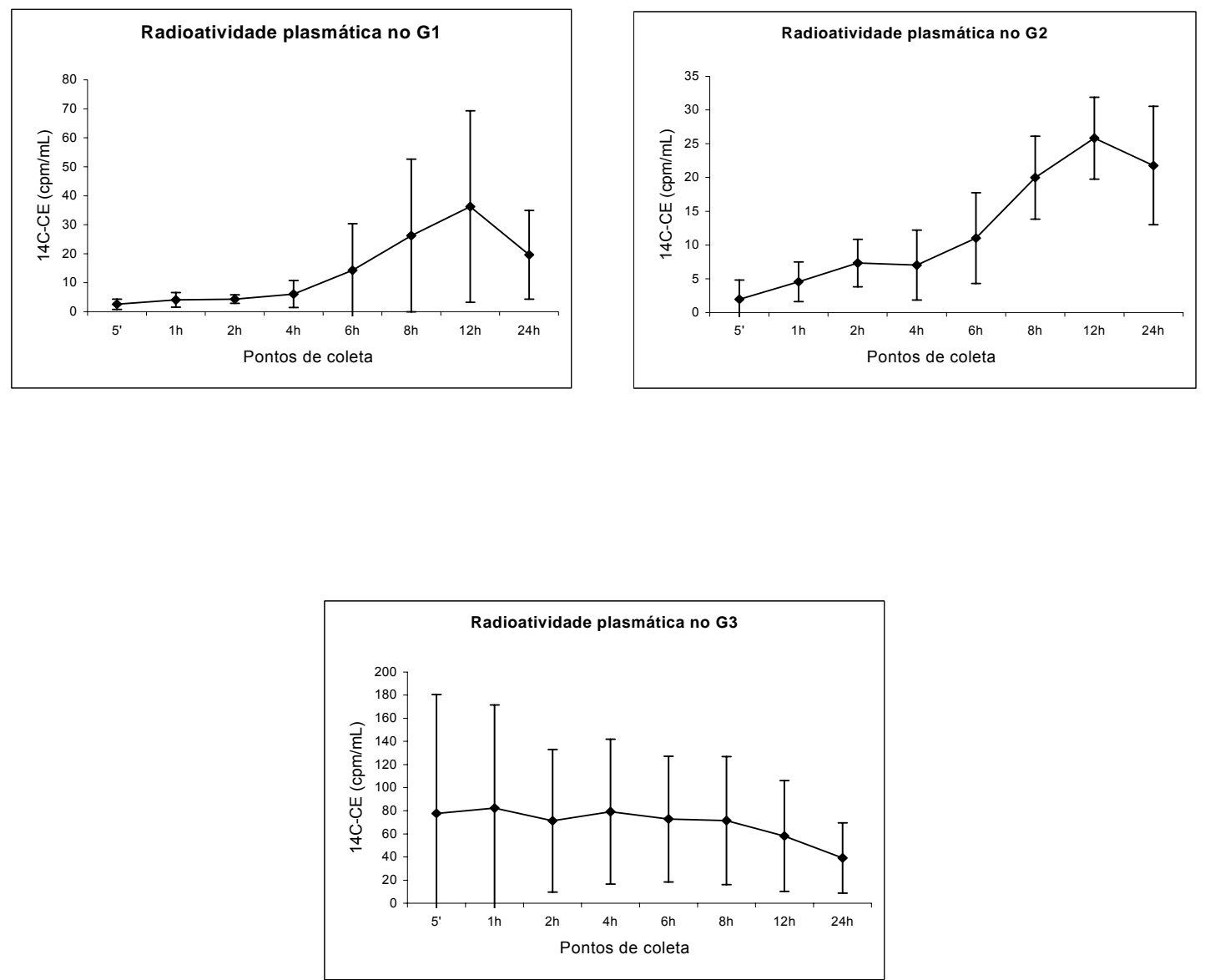

FIGURA 1. Curvas relativas à radioatividade $(\mathrm{cpm} / \mathrm{ml})$ encontrada no plasma coletado até 24 horas após a injeção de LDE nos três grupos de estudo 
Por fim, a tentativa de correlacionar a captação da LDE nos diferentes tecidos - normal, tumoral e linfonodos - com o peso da mama, peso do tumor e relação peso do tumor/peso da mama, em cada um dos grupos, não apresentou resultados consistentes (Tabela 6).

No tangente à tolerabilidade do procedimento, em nenhuma paciente houve queixa de dor ou desconforto durante a injeção da preparação. Tampouco foram observados sinais flogísticos ou outros na região abordada nas horas que decorreram entre a injeção da LDE e o ato cirúrgico.

TABELA 6. Correlação do peso da mama, peso do tumor e porcentagem do tumor em relação à mama com a de captação da LDE em tecido normal, tecido tumoral e linfonodos

\begin{tabular}{lllll} 
Variáveis & Grupos & \multicolumn{2}{l}{ Local de captação da LDE } \\
\cline { 2 - 4 } & & Tecido normal & Tecido tumoral & Linfonodos \\
\hline Peso da mama & G1 & $-\mathbf{0 , 9 1}$ & $-\mathbf{0 , 8 5}$ & $\mathbf{0 , 9 0}$ \\
& G2 & 0,63 & $-0,52$ & 0,41 \\
& G3 & 0,33 & $-0,53$ & $-0,20$ \\
Peso do tumor & & & & \\
& G1 & $-0,62$ & $-\mathbf{0 , 8 0}$ & $\mathbf{0 , 7 4}$ \\
& G2 & $-0,92$ & 0,06 & $\mathbf{0 , 9 2}$ \\
& G3 & 0,01 & 0,05 & $-0,10$ \\
Proporção tumor/mama & G1 & $-0,58$ & & $-0,70$ \\
& G2 & $-0,99$ & $-0,75$ & $\mathbf{0 , 9 9}$ \\
& G3 & 0,22 & $-0,18$ & 0,02 \\
\hline
\end{tabular}




\section{DISCUSSÃO}

No presente trabalho, a administração da LDE por injeção intralesional, nos pacientes G3, foi a mais eficaz entre as três técnicas testadas no protocolo experimental. Esta assertiva baseia-se, primordialmente, no fato de com esta técnica se haver conseguido uma concentração de radioatividade da LDE por grama de tecido apreciavelmente maior do que com as duas outras técnicas de injeção. Além disso, comparativamente ao tecido mamário normal, foi em G3 que se observou a maior relação de captação pelo tumor. Finalmente, a injeção direta no tumor resultou em maior captação pelo linfonodo axilar em comparação com as outras técnicas.

Como explicação plausível da maior captação da LDE em G3, devem ter contribuído para isso não só o fator físico, ou seja, a deposição direta da preparação no tumor; a estrutura histológica tumoral, com pouca gordura e menos espaço intersticial comparado com o tecido mamário normal, sua vascularização característica e anômala possivelmente devem ter facilitado a difusão e retenção da LDE no tumor. As mesmas razões devem ter dificultado a penetração da LDE no tumor quando foi feita injeção $5 \mathrm{~cm}$ afastada do tumor, em G1 ou peritumoral, em G2.

Por outro lado, foi um tanto surpreendente o fato de em G3 havermos obtido maior captação pelo linfonodo do que em G1 e G2.

Quando se injetam corantes no tecido mamário normal, eles atingem 
os vasos linfáticos e região retroareolar e, por via subdérmica, encaminhamse à região axilar, marcando aí os linfonodos. É possível que, no caso da injeção intralesional, a LDE tenha seguido com mais facilidade para a região axilar, fazendo um curto-circuito neste percurso, daí o ter-se obtido concentração maior da nanoemulsão nos linfonodos de G3 do que em G2 e G1. Nesta analogia que fizemos com os corantes, é bom lembrar, no entanto, que eles são moléculas hidrofílicas, enquanto a LDE é constituída de macroagregados moleculares, ou seja são totalmente diversas as propriedades físico-químicas para difusão nos meios e passagem ou por barreiras existentes nas estruturas onde são injetados.

Um outro aspecto interessante em nossos resultados refere-se ao tempo de injeção diferente em dois pacientes do G3. Nestes, os pacientes 13 e 14, a LDE foi injetada a apenas duas horas antes da exerese do tumor, ao passo que nos outros pacientes do G3, os pacientes 9, 10, 11 e 12 a injeção foi feita 12 horas antes, como em G1 e G2 (Tabela 4). Seria esperado que nos pacientes 13 e 14 se encontrasse maior quantidade de radioatividade da LDE do que nos outros pacientes de G3, os pacientes 9 a 12, já que houve menos tempo para que a nanoemulsão escapasse do tumor. Como podemos verificar na Tabela 4, esta tendência, no entanto, claramente não ocorreu. Isto sugere, portanto que, uma vez captada pelo tecido tumoral, a LDE tende a ficar retida por um tempo maior, pelo menos durante as 12 horas em que se observaram as pacientes 9 a 12 .

É interessante a comparação dos nossos dados de captação em G3 com os resultados de captação da LDE pelo carcinoma mamário reportados 
por Graziani et al., 200224 horas após a injeção da nanoemulsão por via endovenosa. A comparação é possível porque naquele trabalho quantidades de radioatividade semelhantes às utilizadas em nosso estudo foram injetadas nas pacientes. A média de captação das nossas pacientes do G3 foi por volta de $45.000 \mathrm{cpm} / \mathrm{g}$, enquanto com a injeção da LDE por via sistêmica resultou na média de captação de cerca de $1.000 \mathrm{cpm} / \mathrm{g}$. Portanto, com a técnica de injeção intralesional, obtivemos uma concentração 45 vezes maior do que a obtida por injeção endovenosa. Essas comparações podem ser alvo de critica porque o material tumoral foi colhido em tempos diferentes 12 horas no presente trabalho e 24 hs no de Graziani et al, 2002. Portanto, haveria um tempo maior para que a LDE captada escapasse do tumor, daí os valores de captação mais baixos observados por Graziani et al, 2002. No entanto, a enorme diferença entre os dois conjuntos de dados, de 45 vezes, dificilmente seria justificável apenas pela diferença no tempo de colheita do tecido tumoral.

Em respeito aos dados de cinética plasmática da LDE após a injeção intratumoral, as curvas (Figura 1) tendem a ter caráter aparecimentodesaparecimento no plasma, em contraste com as obtidas nos diversos trabalhos em que a LDE foi injetada por via endovenosa, ou seja, diretamente no compartimento plasmático (Ades et al., 2001; Azevedo et al., 2005; Ginsburg et al., 1982; Graziani et al., 2002; Hungria et al., 1995; Igreja, 2000; Lo Prete, 2005; Maranhão et al., 1986, 1992; 1993; 1994; 1997; 2002; Rodrigues et al., 2005; 2005). Isto está mais claro em G1 e G2; em G3 o componente ascencional da curva, ou seja, "aparecimento" no plasma é menos 
nítido. Sugere que em G3 ocorreu um equilíbrio mais rápido do compartimento "região circunvizinha ao ponto de injeção da LDE" com o compartimento plasmático. Em G1 e G2, este equilíbrio foi mais lento. É interessante notar que o pico de concentração da radioatividade é semelhante nos dois grupos G1 e G2, ocorrendo por volta do tempo 12 horas, bem como a inflexão da curva para o "desaparecimento', registrado no tempo 24 horas; esses fatos ocorreram nos dois grupos com mais nitidez do que em G3.

O câncer de mama é o segundo tipo de câncer mais freqüente no mundo e a primeira causa de morte por câncer no sexo feminino. A estimativa de incidência de câncer de mama na população brasileira para 2008 é de 51 casos novos a cada 100 mil mulheres, ou seja, 49.400 novos casos. Assim, cerca de 40 mil mulheres por ano irão morrer dessa doença, uma vez que não é totalmente possível a prevenção primária dessa neoplasia e que o seu diagnóstico ainda é realizado em estádios já avançados da doença (INCA, 2007). Portanto, a dimensão do problema exige um grande esforço em tecnologia médica para modificar este quadro.

Ao concentrar os quimioterápicos no tecido tumoral e criar uma nova biodistribuição para eles, bastante diferente da obtida com as formulações comerciais desses fármacos, a LDE diminui acentuadamente os efeitos colaterais da quimioterapia, como mostramos em vários trabalhos clínicos (Lo Prete, 2005; Maranhão et al., 2002; Rodrigues et al., 2002; 2005). No presente estudo, mostramos que utilização da via intralesional, para administração da LDE, torna o sistema mais eficiente no sentido de concentrar as partículas de nanoemulsão no seu sítio de ação. Portanto, é de se prever que, 
ao se associar quimioterápicos à LDE, se consiga, utilizando esta via de administração, um direcionamento desses quimioterápicos ao tumor em escala inaudita na literatura. Como em trabalhos anteriores já desenvolvemos a tecnologia de associar estavelmente à LDE a quimioterápicos como oleato de etoposídeo (Lo Prete, 2005)' carmustina (Maranhão et al., 2002) e o oleato de paclitaxel (Rodrigues et al., 2002; 2005), sendo este o fármaco de primeira linha no tratamento do câncer de mama, torna-se visível a possibilidade de utilizar esta nova estratégia como intrumento para otimizar a quimioterapia neoadjuvante no tratamento de carcinoma de mama localmente avançado.

Antman \& Chang, 2000, mostraram a utilização de quimioterapico via intralesional no tratamento do Sarcoma de Kaposi endêmico, cujo um dos fármacos utilizados foi a doxorrubicina lipossomal e obteve resultados muito promissores, com taxas de resposta em torno de $80 \%$, Tanner et al., 2007 também mostraram tratamento intralesional em gliomas malignos com placlitaxel, Tzafriri et al., 2005 desenvolvem modelo matemático para otimização de infusão de drogas intralesional com microesferas (Rebersek et al., 2004).' mostram a evolução do tratamento com drogas intralesional em lesões cutâneas de câncer de mama.Thakur et al, 2003, a diminuição de efeitos colaterais em terapia alvo após infusão de complexo esféricos lipidicos solúveis.

O tratamento da doença depende do estágio do tumor e da avaliação da situação pessoal da paciente, mas geralmente consiste de intervenção cirúrgica representada por remoção do tumor, nos casos precoces ou por mastectomia parcial ou radical nos casos mais avançados. O procedimento 
cirúrgico é seguido de radioterapia e quimioterapia que visam eliminar células neoplásicas eventualmente remanescentes para evitar recorrência ou metastização da doença (Chang, 2005).

Os resultados do nosso estudo, portanto, abrem as portas para futuros estudos clínicos visando testar quimioterápicos como o oleato de paclitaxel associados à LDE para injeção intralesional no carcinoma de mama localmente avançado. 


\section{CONCLUSÕES}

1. A captação da LDE pelo tecido tumoral foi maior quando injetada intralesional do que quando injetada a $5 \mathrm{~cm}$ dele ou na região peritumoral.

2. Quando injetada intralesional a captação da LDE pelo linfonodo axilar também foi maior do que nas outras duas técnicas de injeção.

3. As curvas de aparecimento-desaparecimento plasmático da LDE após a injeção sugerem que quando a LDE é injetada intralesional ela entra mais rapidamente em equilíbrio com o compartimento plasmático.

4. Nossos dados encorajam futuros estudos clínicos para testar o uso da via intralesional de quimioterápicos usados no tratamento do carcinoma de mama, como o paclitaxel, associados à LDE como estratégia para otimizar a quimioterapia neoadjuvante. 


\title{
7. ANEXOS
}

\author{
ANEXO A \\ Registro das explicações do pesquisador ao paciente ou seu representante \\ legal sobre a pesquisa consignando:
}

1) Justificativa e os objetos da pesquisa: A senhora já sabe que tem câncer de mama e está sendo convidada para participar desta pesquisa, se a senhora estiver de acordo, deve assinar este documento. Este projeto tem por objetivo pesquisar uma substância que será injetada em sua mama perto do tumor e não Ihe causará qualquer risco medicamentoso, pois se trata de uma substância que já é encontrada em seu organismo conhecida como lípides que está presente no colesterol que é encontrado em seu sangue e que no futuro poderá auxiliar no tratamento do câncer de mama. Uma vez injetado esta substância em sua mama o seu tratamento cirúrgico será igual ao já estabelecido para a senhora como rotina deste serviço. A cirurgia a que a senhora será submetida vai depender do tamanho do nódulo encontrado em sua mama que será retirado junto com o "linfonodo sentinela", que é uma glândula que fica embaixo de seu braço para diagnóstico, este material vai para o médico patologista e o médico cirurgião fica esperando o resultado para ver quanto deve ser retirado de sua mama, se o linfonodo sentinela for positivo, as glândulas de sua axila devem ser retiradas, isso se chama esvaziamento axilar e este procedimento é o que vem sendo realizado em todas as cirurgias aqui no Hospital São Joaquim. Se a senhora participar desta pesquisa, todo este material será submetido a análise para se observar se a substância injetada apareceu no seu tumor e se a sua axila apresentar células iguais as do tumor se esta substância será também encontrada no que chamamos linfonodos axilares.

2) Procedimentos que serão utilizados e propósitos, incluindo a identificação dos procedimentos que são experimentais: A senhora será submetida a questionário, exame físico completo, coleta de sangue (uma agulha é introduzida em seu braço e é coletada pequena quantidade de sangue para análise), ultra-som de mama (a senhora fica deitada numa maca e o médico passa uma sonda sobre suas mamas e pela televisão ele analisa o tamanho do seu tumor) e mamografia (a senhora tira uma radiografia da mama numa máquina onde as mamas são encaixadas), ultra-som pélvico (onde o médico passa uma sonda na sua barriga para ver rins, fígado e bexiga), raio $X$ de tórax (uma chapa de seus pulmões e coração) e cintilografia óssea (onde a senhora fica deitada e uma máquina tira um raio $X$ do seu corpo todo). Além disso, a senhora fará também anteriormente a cirurgia a localização do Linfonodo sentinela que é um procedimento simples onde será feita uma injeção perto do tumor de sua mama de um material radioativo (a quantidade de radioatividade é mínima e não compromete a sua saúde e nem de seus familiares), para ver a localização do linfonodo, após a localização será feita uma marca com caneta para o médico saber onde fazer a incisão para retirar o linfonodo (esta marca sai com água e sabão depois). No dia da cirurgia, a senhora recebe uma anestesia geral o médico fará a cirurgia e todos os procedimentos já expostos para a senhora. Quando terminar a cirurgia a senhora ficará em uma sala de recuperação anestésica e só então após liberação dos anestesistas a senhora retornará ao seu quarto.

3. Desconfortos e riscos esperados: A coleta de sangue não dói, é uma picada passageira e pode ficar um pouco roxo no local, mas depois sai. A mamografia dói só quando a mama é apertada, mas é necessária e só dói na hora do exame, o ultra-som não dói, estes exames são feitos com máquinas que não entram no seu corpo nem cortam a pele. Após a cirurgia senhora vai receber orientação para tratar do corte, quando tirar o curativo e se houver algum problema, por exemplo, dor muito forte, inflamação, a senhora pode entrar em contato com o nosso serviço que estaremos as ordens para orientá-la.

4. Benefícios que poderão ser obtidos: O maior benefício desta pesquisa é a possibilidade de futuramente mudarmos a via de administração de muitos medicamentos que hoje causam grandes efeitos colaterais nos pacientes. 
5. Procedimentos alternativos que possam ser vantajosos para o indivíduo: Se a senhora não quiser, não precisa participar desta pesquisa, seu tratamento será o mesmo que para outras pacientes que não participam desta pesquisa, a única diferença é que não será injetada essa substância denominada LDE e por conseqüência não será identificada no material retirado da cirurgia. 
ANEXO B

Aprovação do estudo pela Comissão de Ética para Análise de Projetos de Pesquisa (CAPPesq) do Hospital das Clínicas da Faculdade de Medicina da Universidade de São Paulo (HCFMUSP)

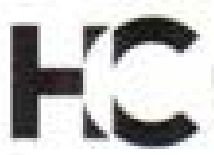

Ao

Departamento de Obstetricla e Ginecologia

O Presidente da Comissào de Ética pora Anblise de Projetos de Pesquiso - CAPPesa da Diretoria Clinica do Hospital das Clnicas e da foculdade de Medicina da Universidade de Sò Poulo. em 17.01.07, tomou ciblncia do execuçăo do Protocolo de Petquíta $n^{\circ} 919 / 05$, intifulado: "Blópsia de lintonodo sentinela em pacientes com carcinoma de mama para avalloçăo do estado linfonodal na pesquisa de Injeçð̄o peri-fumoral da lipoproteina de babxa intensidade (LDE) na metástase axilar e tecido fumorar.

No que tange a suo parte empitica serd desenvolvido no HOSPIAL BENEFICIENCIA PORTUGUESA, tendo seu Comits de Etica oprovado o estudo em 29.11 .06$.

Pesculsador Responsơvel; Dr. Sérglo Mendes

Orientador, Prot. Dr, Raul Cavalcante Maranhăo

Co-orientodor Prot. Dr. Roberto Hegg

CAPpesq. 17 de joneiro de 2007 .

PROF, DR EUCLIDES AYRESS DE CASTIUHO Presidente da Comissbe de Éfica para Análise de Projetos de Pesquiso

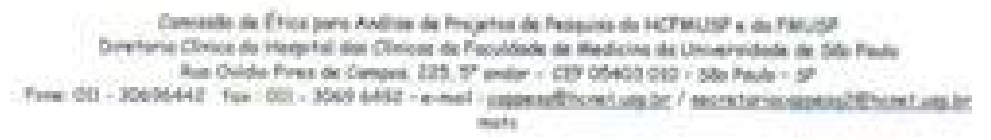


ANEXO C

Aprovação do estudo pelo Comitê de Ética e Pesquisa do Hospital Beneficência Portuguesa (CEPESQ 334/06).

\section{Hospital Beneficência Portuguesa Diretoria Clínica Comitê de Ética em Pesquisa}

\section{Análise de Projeto de Pesquisa}

CEPesq 334/06

"Biópsia de linfonodo sentinela em pacientes com carcinoma de mama para avaliação do estado linfonodal na pesquisa de injeção peri-tumoral da lipoprteina de baixa densidade (LDE) na metástase axilar e tecido tumoral". Pesquisador: Sérgio Mendes

Prezado (a) Senhor (a),

Informamos que o Comitê de Ética em Pesquisa - CEPesp-BP, analisou o Protocolo de Pesquisa acima mencionado, bem como o Termo de Consentimento Livre e Esclarecido apresentado, em reunião de 29 de novembro de 2006, tendo concordado com os pareceres emitidos pelos Relatores designados, optando por Aprová-los.

Solicitamos que encaminhe a esta Comissão, em 6 (seis) meses, um relatório sumário dos resultados preliminares ou definitivos obtidos.

Atenciosamente

São Paulo, 29 de novembro de 2006.

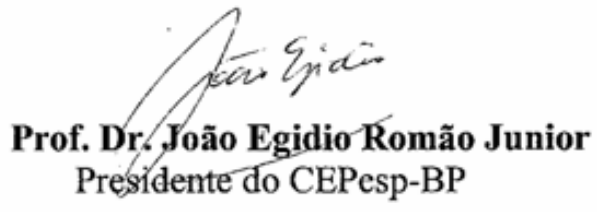


ANEXO D

TABELA 1. Dados de identificação das 14 pacientes incluídas no estudo.

\begin{tabular}{lccc}
\hline Paciente & Iniciais do nome & Idade & Registro geral \\
\hline 1 & LISC & 46 & 2274622 \\
2 & NPG & 87 & 1112063 \\
3 & MLC & 67 & 2284187 \\
4 & AGP & 74 & 2080163 \\
5 & MAL & 57 & 762623 \\
6 & MGDS & 48 & 2294391 \\
7 & HR & 60 & 2306446 \\
8 & GBG & 38 & 2306437 \\
9 & JMS & 61 & 2321980 \\
10 & MACC & 49 & 2323513 \\
11 & MRBS & 63 & 2323526 \\
12 & LMR & 67 & 2334082 \\
13 & MRA & 53 & 2087232 \\
14 & VSLS & 42 & 2334061 \\
\hline
\end{tabular}




\section{REFERÊNCIAS*}

Abdessalan S, Zervor E, Prasad M. Predictors of positive axillary lymph nodes after sentinel lymph node biopsy in breast cancer. Am J Surg 2001; 182:316-20.

Ades A, Carvalho JP, Graziani SR, Amancio RF, Souen JS, Pinotti, JA, Maranhão $\mathrm{RC}$. Uptake of a cholesterol-rich emulsion by neoplasic ovarian tissues. Gynecol Oncol 2001; 81(1):84-7.

Albertini JJ, Lyman GH, Cox C, Yeatman T, Balducci L, Ku N, Shivers S, Berman C, Wells K, Rapaport D, Shons A, Horton J, Greenberg H, Nicosia S, Clark R, Cantor A, Reintgen DS. Lymphatic mapping and sentinel node biopsy in the patient with breast cancer. JAMA 1996; 276:1818.

Alex JC, Krag DN. Gamma-probe guided localization of lymph nodes. Surg 1993; 2:303-8.

Antman K, Chang Y. N. Engl. J. Med., 2000; 342 (14):1027-38.

Azevedo $\mathrm{CH}$, Carvalho JP, Valduga CJ, Maranhão RC. Plasma kinetics and uptake by the tumor of a cholesterol-rich microemulsion (LDE) associated to etoposide oleate in patients with ovarian carcinoma. Gynecol Oncol 2005; $97(1): 178-82$.

* De acordo com:

Adaptado de International Committee of Medical Journals Editors (Vancouver).

Universidade de São Paulo. Faculdade de Medicina. Serviço de Biblioteca e Documentação. Guia de apresentação de dissertações, teses e monografias da FMUSP. Elaborado por Anneliese Carneiro da Cunha, Maria Júlia A. L. Freddi, Maria F. Crestana, Marinalva de S. Aragão, Suely C. Cardoso, Valéria Vilhena, $2^{a}$ ed. São Paulo: Serviço de Biblioteca e Documentação; 2005.

Abreviaturas dos títulos dos periódicos de acordo com List of Journals Indexed in Index Medicus. 
Baillie G, Owens MD, Halbert GW. A synthetic low density lipoprotein capable of supporting U937. J Lipid Res 2002; 43(1):69-73.

Barclay M, Escher GC, Kaufman RJ, Kidder ED, Petermann ML. Human plasma lipoproteins in normal women and in women advanced carcinoma of breast. Cancer 1955; 8:253-60.

Bases RE, Krakoff IH. Studies of serum cholesterol levels in leukemia. J Reticul Soc 1965; 2:8-14.

Bellott R, Pouna P, Robert J. Separation and determination of lipossomal and non-lipossomal daunorubicin from the plasma of patients treated with daunoxone. J Chromatogr 2001; 757:257-67.

Brown MS, Kovanen PT, Goldstein JL. Regulation of plasma cholesterol by lipoproteins receptors. Science 1981; 212:628-35.

Budd D, Ginsberg H. Hypocholesterolemia and acute myelogenous leukemia: Association between disease activity and plasma low-density lipoprotein cholesterol concentrations. Cancer 1986; 58:1361-5.

Cabañas RM. An approach to the treatment of penile carcinoma. Cancer. $1977 ; 39: 455-466$.

Chang AE. Oncology: an evidence-based approach. Philadelphia: Springer; 2005.

Chu AC, Tsang SY, Lo EH, Fung KP. Low density lipoprotein as a targeted carrier for doxorubicin in nude mice bearing human hepatoma HepG2 cells. Life Sci 2001; 70(5):591-601.

Cox CE, Siddharth SB, McCann CR, Ku NNK, Berman C, Durand K, Bolano M, Wang J, Peltz E, Cox S, Salud C, Reintgen DS, Lyman GH. Lymphatic mapping and sentinel lymph node biopsy in patients with breast cancer. Ann Rev Med 2000; 51:525-42.

De Smidt PC, Van Berkel TJ. Prolonged serum half-life of antineoplastic drug by incorporation into the low density lipoprotein. Cancer Res 1990; 
50(23):7476-82.

Eisenberg S. Plasma lipoprotein conversions: the origins of low-density and high-density lipoproteins. Ann N Y Acad Sci 1980; 348:30-47.

Erickson SK, Cooper AD. Acyl-coenzyme: A cholesterol acyltransferase in human liver. In vitro detection and some characteristics of the enzyme. Metabolism 1980; 10:991-6.

Gal D, MacDonald PC, Porter JC, Smith JW, Simpson ER. Effect of cell density and confluency on cholesterol metabolism in cancer cells in monolayer culture. Cancer Res 1981; 41:473-7.

Genta MLND. Farmacocinética e captação tecidual do paclitaxel associado a nanoemulção (LDE) em pacientes com neoplasia maligna do trato genital feminino [Dissertação]. São Paulo. Faculdade de Medicina, Universidade de São Paulo; 2006.

Ginsburg GS, Small DM, Atkinson D. Microemulsions of phospholipids and cholesterol esters. Protein-free models of low density lipoprotein. $\mathrm{J}$ Biol Chem 1982; 57:8216-27.

Goldstein JL, Anderson RG, Brown MS. Coated pits, coated vesicles and receptor-mediated endocytosis. Nature 1979; 279:679-85.

Gould EA, Winshipt Bhilbin PH. Observation on a "sentinel node" in cancer of the parotid. Cancer 1960; 13:77-8.

Graziani SR, Igreja FAF, Hegg R, Meneghetti C, Brandizzi LI, Barboza R, et al. Uptake of a cholesterol-rich emulsion by breast cancer. Ginecol Oncol 2002; 85:493-7.

Harlow SP, Krag DN. Sentinel lymph node: Why study it? Implications of the B-32 study. Semin Surg Oncol 2001; 20:224-7.

Hartveit F, Lilleng PK. Breast cancer: Two micrometastatic variants in the axialla that differ in prognoses. Histopathology 1996; 28:241.

Henriksson P, Eriksson M, Ericsson S, Rudling M, Stege R, Berglund L, 
Angelin B. Hypocholesterolemia and increased elimination of low-density lipoproteins in metastatic cancer of prostate. Lancet 1989; 2:1178-80.

Hirata RD, Hirata MH, Mesquita $\mathrm{CH}$, Cesar TB, Maranhão RC. Effects of apolipoprotein B-100 on the metabolism of a lipid microemulsion model in rats. Biochim Biophys Acta 1999; 53:1437.

Ho YK, Smith GL, Brown MS, Goldstein JL. Low-density lipoprotein (LDL) receptor activity in human acute myelogenous leukemia cells. Blood 1978; 52:1099-14.

Hungria TMV, Chiattone CS, Barros JC, Latrilha MC, Pileggi F, Chamone DAF, Maranhão RC. Plasma lipids and apolipoproteins in multiple myeloma patients. Blood 1995: 86:836.

Igreja FAF. Estudo da captação tumoral de uma emulsão lipídica em pacientes portadoras de carcinoma de mama. [Dissertação]. São Paulo. Faculdade de Medicina, Universidade de São Paulo; 2000.

INCA - Instituto Nacional do Câncer. Câncer de mama: estimativas para 2008. Acesso em: 18 de novembro de 2007. Disponível em: http://www.inca.gov.br/estimativa/2008.

Iribarren C, Reed DM, Chen R, Yano K, Dwyer JH. Low serum cholesterol and mortality: Which is the cause and which is the effect? Circulation 1995; 92:2396-2405.

Kader A, Davis PJ, Kara M, Liu H. Drug targeting using low density lipoprotein (LDL): Physochemical factors affecting drug loading into LDL particles. J Control Release 1998; 55(2-3):231-73.

Kamath V, Giulianao R, Davway E. Characteristics of the sentinel lymph node in breast cancer predict further involvement of higher-echelon nodes in axial: A study to evaluate the need for complete axillary lymph node dissection. Arch Surg 2001; 136:688-92.

Keshtgar MRS, Waddington WA, Lakhain SR, Ell PJ. The sentinel node in surgical oncology. Editor MRS 2000. 
Kinmonth JB, Taylor G. The lymphatic evaluation in lymphedema. Ann Surg 1952; 132:129-36.

Klimberg H, Tillman RS, Korkourian SI, Korkourian I, Rubio IT, Mancino AT. Intraoperative touch prep for sentinel lymph node biopsy: A 4-year experience. Ann Surg Oncol 2002; 9:333-9.

Knapp ML. Alterations of serum lipids in breast cancer: Effects of disase activity, treatment and hormonal factors. Clin Chem Winston-Salem 1991; 37:2093-101.

Krag D, Weaver D, Ashikaga T, Moffat F, Klimberg VS, Shriver C, Feldman S, Kusminsky R, Gadd M, Kuhn J, Harlow S, Beitsch P. The sentinel node in breast cancer: A multicenter validation study. N Engl J Med 1998; 337:941.

Krag DN, Weaner DL, Alex JC, Fairbank JT. Surgical resection and radiolocalization of the sentinel lymph node in breast cancer using a gamma probe. Surg Oncol 1993; 2:335-9.

Kretzer IF. Efeito da terapia antitumoral combinada LDE-oleato de paclitaxel e de LDE-oleato de etoposídeo em melanoma murino. [Dissertação]. São Paulo. Faculdade de Medicina, Universidade de São Paulo; 2007.

Lo Prete AC. Toxicidade e ação antitumoral de um derivado do quimioterápico etoposídeo (oleato de etoposídeo) associado a uma emulsão rica em colesterol. [Dissertação]. São Paulo. Faculdade de Medicina, Universidade de São Paulo; 2005.

Lockett MA, Baron PL, O'Brien PH, Elliott BM, Robison JG, Maitre N, Metcalf JS, Cole DJ. Detection of occult breast cancer micrometastases in axillary lymph nodes using a multimarker reverse transcriptase-polymerase chain reaction panel. J Am Coll Surg 1998; 187:9-16.

Lundberg BO. Preparation of drug-low density lipoprotein complexes for delivery of antitumoral drugs via the low density lipoprotein pathway. Cancer Res 1987; 47:4105-8.

Mahley RW, Innerarity TL, Rall Jr SC, Weisgraber KH. Plasma lipoproteins: 
Apolipoprotein structure and function. J Lipids Res NY 1984; 25:1277-94.

Maletinska L, Blakely EA, Bjornstad KA, Deen DF, Knoff J, Forte TM. Human gioblastoma cell lines: levels of low-density-lipoprotein receptor and lowdensity lopoprotein receptor-related protein. Cancer Res 2000; 60:2300-3.

Maranhão RC, Cesar TB, Pedroso-Mariani SR, Hirara MH, Mesquita $\mathrm{CH}$. Metabolic behavior in rats of a nonprotein microemulsion resembling low density lipoprotein. Lipids 1993; 28:691-6.

Maranhão RC, Garicochea B, Silva E, Llacer PD, Cadena SMS, Coelho IJC, Meneghetti JC, Pileggi FJ, Chamone DA. Plasma kinetics and biodistribution of a lipid emulsion resembling low-density lipoprotein in patients with acute leukemia. Cancer Res 1994; 54:4660-6.

Maranhão RC, Garicochea B, Silva E, Llacer PD, Pileggi FJC, Chamone DAF. Increased plasma removal of microemulsions resembling the lipid phase of low-density lipoproteins (LDL) in patients with acute myeloid leukemia: a possible new strategy for treatment of the disease. Brazilian $\mathrm{J}$ Med Biol Res 1992; 25:1033-7.

Maranhão RC, Graziani SR, Yamaguchi N, Melo RF, Latrilha MC, Rodrigues DG, Couto RD, Schreier S, Buzaid AC. Association of carmustine with a lipid emulsion: In vitro, in vivo and preliminary studies in cancer patients. Cancer Chem Pharmacol 2002; 49(6):487-98.

Maranhão RC, Roland IA, Toffoletto O, Ramires JA, Gonçalves RP, Mesquita $\mathrm{CH}$, Pileggi F. Plasma kinetic behaviour in hyperlipidemic subjects of a lipid microemulsion that binds to low density lipoprotein receptors. Lipids 1997; 32(6):627-33.

Maranhão RC, Teryac AM, Redgrave TG. Effects of cholesterol content on metabolism of protein-free emulsion models of lipoprotein. Biochem Biophys Acta 1986; 875:247-55.

Mariani G, Moresco L, Viale G, Villa G, Bagnasco M, Canavese G, Buscombe J, Strauss HW, Paganelli G. Radioguided sentinel lymph node 
biopsy in breast cancer surgery. J Nucl Med 2001; 42:1198-215.

Masquelier M, Vitols S, Palsson M, Mars U, Larson BS, Peterson CO. Low density lipoprotein as a carrier of cytostatics in cancer chemotherapy: Study of stability of drug-carrier complexes in blood. J Drug Target 2000; 8(3):15564.

Masquelier M, Vitols S, Peterson C. Low density lipoprotein as a carrier of antitumoral drugs: In vivo fate of drug-human low-density lipoprotein complexes in mice. Cancer Res 1986; 46(8):3842-7.

Mori M, Mimori K, Inoue M, Barnard GF, Tsuji K, Nanbara S, Ueo H, Akiyoshi T. Detection of cancer micrometastases in lymph nodes by reverse transeriptase polymerase chain reaction. Cancer Res 1995; 55:3417.

Nasser IA, Lee AK, Bosari S, Saganich R, Heatley G, Silverman ML. Occult axillary lymph node metastatses in "node-negative" breast carcinoma. Hum Pathol 1993; 24:950-7.

Niendorf A, Nagete H, Gerding D, Meyer-Pannwn O, Gebbardi A. Increased LDL receptor mRNA expression in colon cancer is correlated with a rise in plasma cholesterol levels after curative surgery. Int J Cancer 1995; 61:461-4.

Nydegger UE. Serum lipoprotein levels in patients with cancer. Cancer Res 1972; 32(8):1756-60.

Pekkanen J, Nissinen A, Vartanen B, Salonen JL, Punsar S, Karnoven MJ. Changes in serum cholesterol levels and mortality, a 30-follow-up, the finish cohorts of the seven countries study. Am J Epidemol 1999; 139:155-65.

Rahusen F, Torrenga H, Vandiest P. Predictive factors for metastatic involvement of nonsentinel nodes in patients with breast cancer. Arch Surg 2001; 136:1059-63.

Ratanawichtrasin A, Biscott CV, Levy L, Crowe JP. Touch imprint cytological analysis of sentinel lymph nodes for detecting axillary metastases in patients with breast cancer. Br J Surg 1999; 86:1346-8. 
Rebersek M, Cufer T, Cemazar M, Kranjc S, Sersa G. Electrochemotherapy with cisplatin of cutaneous tumor lesions in breast cancer. Anticancer Drugs. 2004 Jul;15(6):593-7

Rensen PC, Schiffelers RM, Versluis AJ, Bijstrbosch MK, Van KuijkMeuwissen ME, Van Berkel TJ. Human recombinant apoliprotein E-enriched liposomes can mimic low-density lipoproteins as carriers for the site-specific delivery of antitumor agents. Mol Pharmacol 1997; 52(3):445-55.

Rimsten A, Johansson $H$, Stenkvist B. Perioperative diagnosis of axillary lymph nodes in cancer of the breast. Surg Gynecol Obstet 1974; 139:551-4.

Rodrigues DG, Covolan CC, Coradi ST, Barboza R, Maranhão RC. Use os a cholesterol-rich emulsion that binds to low-density lipoprotein receptors as a vehicle for paclitaxel. J Pharm Pharmacol 2002; 54:765-72.

Rodrigues DG, Maria DA, Fernandes DC, Valduga CJ, Couto RD, Ibañez COM, Maranhão RC. Improvement of paclitaxel therapeutic index by derivatization and association to a cholesterol-rich microemulsion: In vitro an in vivo studies. Cancer Chemother Pharmacol 2005; 55:565.

Rosser RJ. A point of view: Trauma is the cause of occult micrometastatic breast cancer in sentinel axillary lymph nodes. Breast J 2000; 6:209-12.

Rubio IT, Korkourian S, Cowan C, Krag DN, Colvert M, Klimberg VS. Use of touch preps for intraoperative diagnosis of sentinel lymph node metastases in breast cancer. Ann Surg Oncol 1998; 5:689-94.

Rudling MJ, Collins VP, Peterson CO. Delivery of aclacinomycin A to human glioma cells in vitro by the low density lipoprotein pathway. Cancer Res 1983; 43:4600-5.

Rudling MJ, Stahle L, Peterson CO, Skogg L. Content of low density liproprotein receptors in breast cancer tissue related to survival of patients. $\mathrm{Br}$ Med J 1986; 292:580-2.

Samadi-Baboli M, Favre G, Canal P, Soula G. Low density lipoprotein for 
cytotoxic drug targeting: Improved activity of elliptinium derivative against B16 melanoma in mice. Br J Cancer 1993; 68:319-26.

Tanner PG,Holtmannpötter M,TonnJC, Goldbrunner R. Effects of drug efflux on convection-enhanced paclitaxel delivery to malignant gliomas: technical note. Neurosurgery. 2007 61(4):E880-2;

Thakur ML, Coss R, Howell R, Vassileva-Belnikolovska D, Liu J, Rao SP, Spana G, Wachsberger P, Leeper DL. Role of lipid-soluble complexes in targeted tumor therapy. J Nucl Med. 2003 Aug;44(8):1293-300.

Tokui T, Takatori T, Shinozaki N, Ishigami M, Shiraishi A, Ikeda T, Tsuruo T. Delivery and cytotoxicity of RS-1541 in St-4 human gastric cancer cells in vitro by the low-density-lipoprotein pathway. Cancer Chemother Phamacol 1995; 36(1):1-6.

Turner RR, Oilila DW, Krasne DL, Guiliano AE. Histopathologic validation of the sentinel node hypothesis for breast carcinoma. Ann Surg 1997; 226:271.

Turner-Warwick RT. The lymphatic of the breast. Br J Surg 1959; 46:574-82.

Tzafriri AR, Lerner El, Flashner-Barak M, Hinchcliffe M, Ratner E, Parnas H. Mathematical modeling and optimization of drug delivery from intratumorally injected microspheres. Clin Cancer Res. 2005 Jan 15;11(2 Pt 1):826-34.

Ueyama Y, Matsuzawa U, Yamashita S, Funashashi T, Sakai N, Nakamura $\mathrm{T}$, et al. Hypocholesterolemic factor from gallbaldder cancer cells. Lancet 1990; 336:707-9.

Verluis AJ, Van Geel PJ, Oppelaar H, Van Berkel TJC, Bijterbosch MK. Receptor-mediated uptake of low-density lipoprotein by B16 melanoma cells in vitro and in vivo in mice. Br J Cancer 1996; 74:525-32.

Veronesi U, Paganelli G, Galimberti V, Viale G, Zurrida S, Bedoni M, Costa A, de Cicco C, Geraghty JG, Luini A, Sacchini V, Veronesi P. Sentinel-node biopsy to avoid axillary dissection in breast cancer witch clinically negative lymph-nodes. Lancet 1997; 11:1864-7. 
Villman K, Öhd JF, Lidbrink E, Malmberg L, Lindh B, Blomqvist C, Nordgren $H$, Bergh J, Bergström D, Ahlgren J. A phase II study of epirubicin, cisplatin and capecitabine as neoadjuvant chemotherapy in locally advanced or inflammatory breast cancer. Eur J Cancer 2007; 43(7):1153-60.

Vitols S, Soderberg-Reid K, Masquelier M, Sjostrom B, Peterson C. Low density lipoprotein for delivery of a water-insoluble alkylating agent to malignant cells. In vitro and in vivo studies of a drug-lipoprotein complex. $\mathrm{Br} \mathrm{J}$ Cancer 1990; 62(5):724-9.

Xiao W, Wang L, Ryan JM, Pater A, Liu H. Incorporation of an (125)I-labeled hexa-iodinated diglyceride analog into low-density lipoprotein and high specific uptake by cells of cervical carcinoma cell lines. J Drug Target 1999; 152(3):250-6. 